Sādhanā Vol. 40, Part 5, August 2015, pp. 1501-1529. (C) Indian Academy of Sciences

\title{
Harmonic analysis of DC capacitor current in sinusoidal and space-vector modulated neutral-point-clamped inverters
}

\author{
GOPALAKRISHNAN K S* and G NARAYANAN \\ Department of Electrical Engineering, Indian Institute of Science, \\ Bangalore 560012, India \\ e-mail: ashwinkrishnan121@gmail.com; gnar@ee.iisc.ernet.in
}

MS received 25 August 2014; revised 19 February 2015; accepted 24 May 2015

\begin{abstract}
The voltage ripple and power loss in the DC-capacitor of a voltage source inverter depend on the harmonic currents flowing through the capacitor. This paper presents a double Fourier series based analysis of the harmonic contents of the DC capacitor current in a three-level neutral-point clamped (NPC) inverter, modulated with sine-triangle pulse-width modulation (SPWM) or conventional space vector pulse-width modulation (CSVPWM) schemes. The analytical results are validated experimentally on a 3-kVA three-level inverter prototype. The capacitor current in an NPC inverter has a periodicity of $120^{\circ}$ at the fundamental or modulation frequency. Hence, this current contains third-harmonic and triplen-frequency components, apart from switching frequency components. The harmonic components vary with modulation index and power factor for both PWM schemes. The third harmonic current decreases with increase in modulation index and also decreases with increase in power factor in case of both PWM methods. In general, the third harmonic content is higher with SPWM than with CSVPWM at a given operating condition. Also, power loss and voltage ripple in the DC capacitor are estimated for both the schemes using the current harmonic spectrum and equivalent series resistance (ESR) of the capacitor.
\end{abstract}

Keywords. Capacitor current; capacitor loss; conventional space vector pulse width modulation; diode-clamped inverter; double Fourier series; harmonic analysis; neutralpoint-clamped inverter; sine-triangle pulse width modulation; three-level inverter.

\section{Introduction}

Inverters used in high power applications with medium to high DC-bus voltages require either switching devices of high voltage rating or series connection of devices of lower voltage rating. While the devices of higher voltage rating might be unavailable or expensive, the series connection of devices leads to dynamic voltage sharing problems (Teichmann \& Bernet 2005; Lekha 2013). These led to the development of multi-level inverters (Lekha 2013) in general and threelevel inverters in particular. Multi-level concept enables realization of inverters with DC-bus

${ }^{*}$ For correspondence 
voltages much higher than the ratings of the devices (Rodriguez et al 2010; Kouro et al 2010). Among multi-level inverters, the use of three-level neutral- point-clamped (NPC) inverters is widespread at medium voltage levels (Rodriguez et al 2010; Das 2013). In a three-level inverter, the devices handle only half the DC-bus voltage compared to a two-level inverter. Hence, the voltage stress on the devices is reduced (Teichmann \& Bernet 2005). Consequently, the switching losses are reduced compared to the two-level inverter (Teichmann \& Bernet 2005). The three-level NPC inverter also offers better waveform quality of the output voltage than the twolevel inverter (Das 2013). In spite of all these advantages the three-level NPC inverter has a drawback in terms of DC neutral-point imbalance. However, the DC-bus imbalance in a threelevel NPC inverter can be mitigated through appropriate control as has been reported extensively (Orfanoudakis et al 2013a, b; Lee \& Lee 2014; Choi et al 2014).

For control of the switches in two-level and three-level inverters, numerous pulse-width modulation (PWM) strategies have been proposed (Holmes \& Lipo 2003). The most well known and commonly used PWM strategies are sine-triangle pulse width modulation (SPWM) and conventional space vector pulse width modulation (CSVPWM). Extensive study has been carried out on the effects of these schemes on the quality of the load current (Holmes \& Lipo 2003), switching and conduction losses in the devices (Holmes \& Lipo 2003; Orfanoudakis et al 2010; Teichmann $\&$ Bernet 2005). This paper focuses on the harmonic analysis of the DC capacitor current in the NPC inverter, and the influence of PWM method on the spectral components of the capacitor current.

The capacitor RMS current plays a pivotal role in choosing a capacitor (Kieferndorf et al 2004). Analytical estimation of the capacitor RMS current in three-level NPC inverter has been presented in (Gopalakrishnan et al 2011; Orfanoudakis et al 2013a, b ). If the equivalent series resistance (ESR) of the capacitor is independent of frequency, then the capacitor RMS current itself can give a good estimate of the power loss in the capacitor (Kolar \& Round 2006). However, the ESR of the capacitor is typically a function of frequency (Gasperi 1997). Hence, for accurate determination of capacitor power loss, it is important to evaluate the harmonic contents of the DC-link capacitor current (Bierhoff \& Fuchs 2008).

The harmonic spectrum of the output voltage has been studied extensively for both two-level (Holmes \& Lipo 2003; Moynihan et al 1998) and three-level inverters (Holmes \& Lipo 2003; McGrath \& Holmes 2002). Harmonic analysis of the DC-capacitor current in a two-level inverter based on double Fourier series and geometric wall model (Holmes \& Lipo 2003) is presented in (Bierhoff \& Fuchs 2008). A brief description on the utilization of this technique for determination of harmonic spectrum of DC-link current for three-level diode-clamped inverter for SPWM scheme is given in (Orfanoudakis et al 2013a, b). This paper presents a detailed discussion on the application of the above techniques to the harmonic analysis of DC-link current in a three-level inverter for SPWM as well as CSVPWM schemes. While only simulation results have been presented in (Orfanoudakis et al 2013a, b), the analytical results are validated extensively through experiments in this paper. The harmonic spectra of the DC-capacitor current pertaining to both the schemes are compared. Finally, the harmonic spectrum is used to evaluate the DC capacitor power loss in both the schemes. Some preliminary results of this work have been presented in (Gopalakrishnan \& Narayanan 2013), where the discussion is restricted to the SPWM scheme.

The instantaneous DC-link current in a three-level NPC inverter is discussed in Section 2. Harmonic analysis of the DC-link current based on double Fourier series and geometric wall model techniques is presented in Section 3. Sections 4 and 5 deal with the evaluation of the harmonic components in DC-link current for SPWM and CSVPWM schemes, respectively. The results of the analysis are validated experimentally on a 3-kVA NPC inverter. The analytical and measured harmonic spectra of the capacitor current are compared in Section 6. The harmonic currents are 
used to evaluate the power loss and voltage ripple in the DC-link capacitor in Section 7 and 8. The conclusions are presented in Section 9.

\section{Instantaneous DC-link current in an NPC inverter}

The power circuit of a three-level neutral-point-clamped inverter is shown in figure 1. The load terminals R, Y and B are connected to the mid-points of the three legs of the inverter. Each load terminal can be connected to the positive DC terminal, or to the negative DC terminal, or to the DC mid-point ' $O$ ' using the switching devices in each leg. Each leg is essentially a single-pole triple-throw switch with the load terminal being the pole. The pole voltage $v_{R O}$ equals $+0.5 V_{D C}$, 0 or $-0.5 V_{D C}$, depending on the states of the switches in the R-phase leg as shown in table 1.

A binary function which indicates the state of a switching device (i.e. whether ON or OFF) is termed as a switching function. The switching function for the R-phase top switches for example is expressed as $S_{R 1}$ and $S_{R 2}$. The switching function for a device takes the value of either 1 or 0 depending on whether the device is 'ON' or 'OFF'.

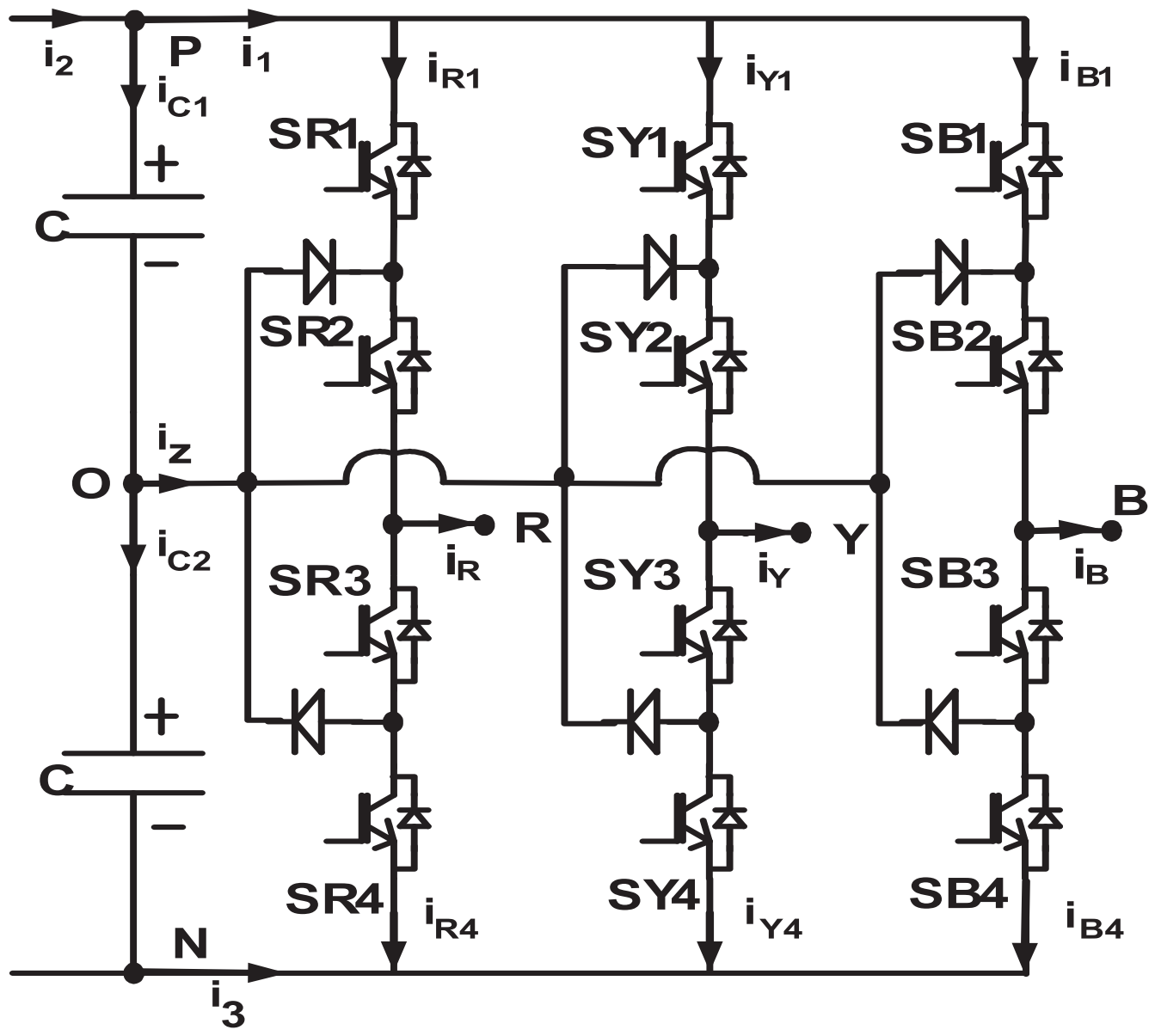

Figure 1. Three-level neutral-point-clamped inverter. 
Table 1. Switch states and pole voltages.

\begin{tabular}{lcccc}
\hline SR1 & SR2 & SR3 & SR4 & Pole voltage $v_{R O}$ \\
\hline ON & ON & OFF & OFF & $0.5 V_{D C}$ \\
OFF & ON & ON & OFF & 0 \\
OFF & OFF & ON & ON & $-0.5 V_{D C}$ \\
\hline
\end{tabular}

The R-phase current, for example, flows into the positive DC-link terminal only when the devices SR1 and SR2 are 'ON', i.e. $S_{R 1}=S_{R 2}=1$. Similar observation can be made regarding the other two phases as well. Therefore, the DC-link current $i_{1}$ can be expressed in terms of the three-phase currents $\left(i_{R}, i_{Y}, i_{B}\right)$ and the switching functions of the top two devices in each leg as shown below:

$$
i_{1}=S_{R 1} S_{R 2} i_{R}+S_{Y 1} S_{Y 2} i_{Y}+S_{B 1} S_{B 2} i_{B} .
$$

Whenever the top device SR1 is 'ON', the device SR2 is also 'ON' as can be seen from table 1. Hence, the expression for the instantaneous DC-link current reduces to the following:

$$
i_{1}=S_{R 1} i_{R}+S_{Y 1} i_{Y}+S_{B 1} i_{B}
$$

The harmonic content of the line current in a sinusoidally modulated NPC inverter is quite low when the switching frequency and line side inductance are sufficiently high (Holmes \& Lipo 2003; McGrath \& Holmes 2002). Since these line current harmonics are insignificant to influence the DC-link current (Bierhoff $\&$ Fuchs 2008), the three-phase load currents $i_{R}, i_{Y}$ and $i_{B}$ can be expressed as shown in (3), where $I_{M}$ is the peak fundamental current, and $\phi$ is the load power factor angle.

$$
\begin{aligned}
& i_{R}=I_{M} \sin (\omega t-\phi) \\
& i_{Y}=I_{M} \sin \left(\omega t-\frac{2 \pi}{3}-\phi\right) \\
& i_{B}=I_{M} \sin \left(\omega t+\frac{2 \pi}{3}-\phi\right) .
\end{aligned}
$$

As seen from (3), the three-phase instantaneous currents depend on the peak fundamental current $I_{M}$ and power factor angle $\phi$. The switching functions depend on modulation index $M$, carrier frequency $f_{c}$, and the PWM method employed. Hence the instantaneous DC-link current depends on $I_{M}, \phi, M, f_{c}$ and the PWM scheme. Therefore, the harmonic spectrum of the DC-link current also depends on the above operating parameters and the PWM method. The purpose of this paper is to study the spectral composition of the DC-link current pertaining to sine-triangle PWM and conventional space vector PWM schemes at various operating conditions of an NPC inverter. The spectral composition of the DC-link current is closely related to that of the DC capacitor current as discussed below.

Each term in the right hand side (RHS) of Eq. (2) is a product of a switching function and a phase current. Each frequency in such a product of two periodic quantities would be either the sum or difference of a frequency contained in the first quantity and a frequency in the second. Only the modulation frequency component is significant in the phase current as discussed earlier. But each switching function consists of a DC component, low-frequency AC components (i.e. modulation frequency and low-order harmonics) and high-frequency AC components (i.e. switching frequency components). 
In order to first gain an understanding of the low-frequency components, the duty ratios of the top devices in the three legs are considered, which are defined in (4). Each duty ratio consists of only the DC and low-frequency AC components of the corresponding switching function.

$$
\begin{aligned}
& d_{R 1}=\quad M \sin (\omega t) \quad 0<\omega t<\pi \\
& d_{R 1}=\quad 0 \quad \pi<\omega t<2 \pi \\
& d_{Y 1}=M \sin (\omega t-2 \pi / 3) \quad 2 \pi / 3<\omega t<5 \pi / 3 \\
& d_{Y 1}=0 \quad 0<\omega t<2 \pi / 3 \quad \text { and } 5 \pi / 3<\omega t<2 \pi \\
& d_{B 1}=M \sin (\omega t-4 \pi / 3) \quad 0<\omega t<\pi / 3 \quad \text { and } \quad 4 \pi / 3<\omega t<2 \pi \\
& d_{B 1}=\quad 0 \quad \pi / 3<\omega t<4 \pi / 3 \text {. }
\end{aligned}
$$

The switching-cycle-averaged DC-link current, defined in (5), consists of the DC and lowfrequency AC components of the instantaneous DC-link current. Subtracting the DC component, this quantity is shown plotted in figure 2 for $M=0.9$ and $M=0.6$, considering power factors of 0.844 and 0.137 at each $M$. One can see that the DC-link current consists of triplen frequency harmonic currents, and particularly the third harmonic. One can also see that the amplitude of the third harmonic is sensitive to both modulation index and power factor.

$$
i_{1}=d_{R 1} i_{R}+d_{Y 1} i_{Y}+d_{B 1} i_{B}
$$

Of the DC, low-frequency and high-frequency components in the instantaneous DC-link current, the DC component cannot flow through the electrolytic capacitors and is supplied by the DC power supply or rectifier, feeding the NPC inverter. Obviously, the entire high-frequency currents flow through the DC capacitors as these offer very low reactances to these components.

The DC capacitors are assumed here to be large enough that these offer low enough reactances to the low-frequency AC components as well; hence, the entire third harmonic and triplen frequency components are also assumed to flow through the DC capacitors. Such an assumption also helps evaluation of worst-case RMS current through the capacitor and worst-case voltage ripple across the capacitor. Hence, referring to figure 1, the DC capacitor current $\left(i_{C 1}\right)$ is the difference between the DC-link current $\left(i_{1}\right)$ and the average value of the DC-link current $\left(i_{2}\right)$. Hence the harmonic analysis of the DC capacitor current is carried out as that of the DC-link current. The purpose of this paper is to study in detail the spectral composition of the DC-link current, pertaining to sine-triangle PWM and conventional space vector PWM schemes, at various operating conditions on the NPC inverter. For both the PWM methods, the spectral analysis is carried out using Double Fourier Series, which is discussed in the following section.

\section{Harmonic analysis of DC-link current}

This section gives a general insight into the Double Fourier method for harmonic analysis of DC-link current, which is common for any general modulating signal. The DC-link current $i_{1}$ is the sum of the top switch currents of the three phases, namely $i_{R 1}, i_{Y 1}$ and $i_{B 1}$ as shown in (6). Hence, the harmonic analysis of the DC-link current $i_{1}$ can be broken up into those of the topswitch currents $i_{R 1}, i_{Y 1}$ and $i_{B 1}$. Since these three currents are symmetric, the harmonic analysis of one of them (say $i_{R 1}$ ) would suffice.

$$
i_{1}=i_{R 1}+i_{Y 1}+i_{B 1}
$$



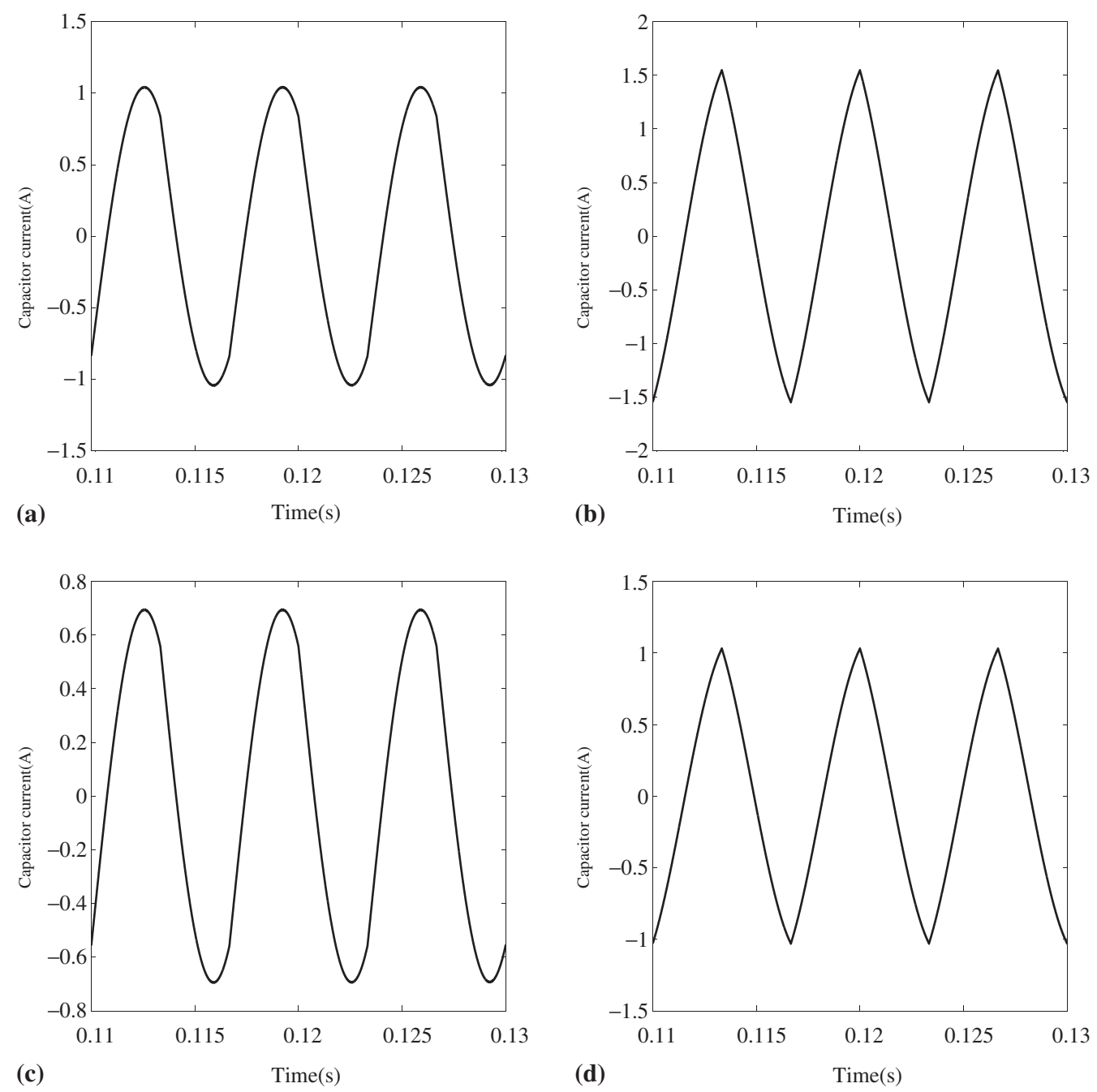

(c)

Time(s)

Figure 2. Switching-cycle-average dc capacitor current waveform at (a) $M=0.9$ and $\cos (\phi)=0.844$; (b) $M=0.9$ and $\cos (\phi)=0.137$; (c) $M=0.6$ and $\cos (\phi)=0.844$; (d) $M=0.6$ and $\cos (\phi)=0.137$ for a load current amplitude of $4 \mathrm{~A}$.

\subsection{Top-switch current in a switching cycle}

For switching the devices in a leg, a modulating signal $\left(f(\omega t)=m_{R}\right)$ is compared against twolevel shifted carriers as shown in figure 3. The load current (say $i_{R}$ ) flows through the top switch (say SR1), whenever the top switch is ON, i.e. when the modulation signal is greater than both the carriers. This is illustrated in figure $3 \mathrm{a}$, which considers a switching cycle corresponding to $m_{R}=0.707$. The top-switch current $\left(i_{R 1}\right)$ is zero otherwise as shown by figure $3 \mathrm{a}$ and figure $3 \mathrm{~b}$; figure $3 \mathrm{~b}$ considers a switching cycle where $m_{R}=-0.3$. These conditions are expressed mathematically as shown in table 2 .

The current $i_{R 1}$ depends on the modulation signal $m_{R}(\omega t)$, and the carriers $g_{1}\left(\omega_{c} t\right)$ and $g_{2}\left(\omega_{c} t\right)$. The modulation signal and the carrier signals depend on $\omega t$ and $\omega_{c} t$, respectively. Hence 

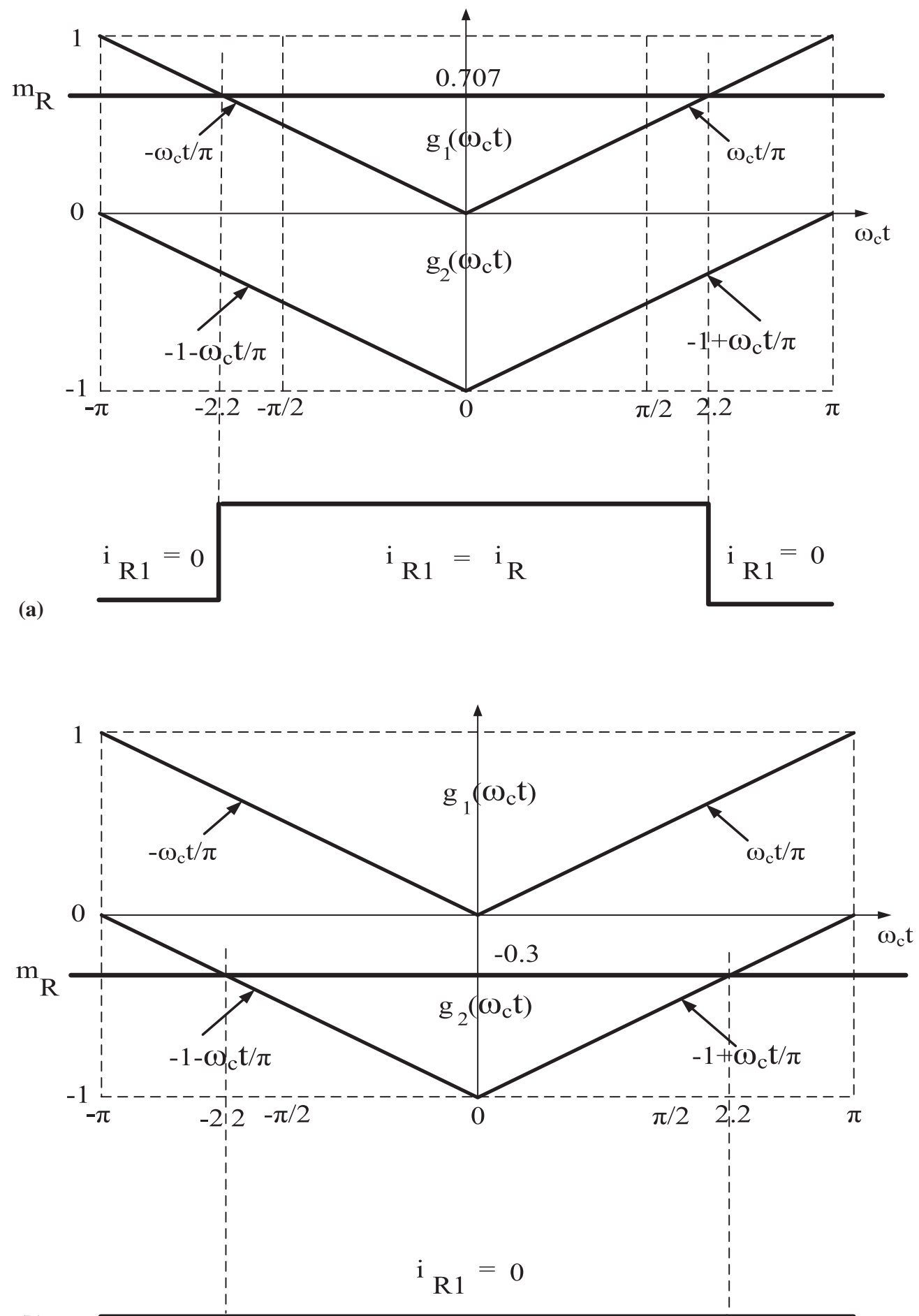

(b)

Figure 3. Top switch current $i_{R 1}$ in a switching cycle when (a) $m_{R}=0.707$ and (b) $m_{R}=-0.3$. 
Table 2. Conditions for determining top-switch current $i_{R 1}$ in a switching cycle.

\begin{tabular}{lcc}
\hline$i_{R 1}$ & When $-\pi \leq \omega_{c} t \leq 0$ & When $0<\omega_{c} t \leq \pi$ \\
\hline$i_{R}$ & $m_{R}>\frac{-\omega_{c} t}{\pi}$ & $m_{R}>\frac{\omega_{c} t}{\pi}$ \\
0 & $\frac{-\omega_{c} t}{\pi}>m_{R}$ & $\frac{\omega_{c} t}{\pi}>m_{R}$ \\
\hline
\end{tabular}

$i_{R 1}$ is a function of two independent variables, namely $\omega t$ and $\omega_{c} t$. Furthermore, $i_{R 1}$ is periodic in both these variables. Hence $i_{R 1}$ is analysed based on double Fourier series (Bierhoff \& Fuchs 2008; Holmes \& Lipo 2003) in this paper.

\subsection{Double Fourier series analysis}

Fourier series is used for expressing periodic functions in one variable as a summation of the DC, fundamental and harmonic components. Similarly, double Fourier series is used to express periodic functions in two variables as summation of DC and sinusoidal components of different frequencies. The frequency of the sinusoidal components can be represented as $m \omega_{c}+n \omega$, where $m$ is a non-negative integer, and $n$ is an integer. The integers $m$ and $n$ are called carrier index and fundamental index, respectively (Holmes \& Lipo 2003). Any function $h\left(\omega t, \omega_{c} t\right)$, which is independently periodic in both $\omega t$ and $\omega_{c} t$, is expressed as given below (Holmes \& Lipo 2003):

$$
\begin{array}{r}
h\left(\omega_{c} t, \omega t\right)=\frac{A_{00}}{2}+\sum_{n=1}^{\infty}\left[A_{0 n} \cos (n \omega t)+B_{0 n} \sin (n \omega t)\right] \\
+\sum_{m=1}^{\infty}\left[A_{m 0} \cos \left(m \omega_{c} t\right)+B_{m 0} \sin \left(m \omega_{c} t\right)\right] \\
+\sum_{m=1}^{\infty} \sum_{n=-\infty_{n \neq 0}}^{\infty}\left[A_{m n} \cos \left(m \omega_{c} t+n \omega t\right)+B_{m n} \sin \left(m \omega_{c} t+n \omega t\right)\right] .
\end{array}
$$

The coefficients $A_{m n}$ and $B_{m n}$ for various integral values of $n$ and non-negative integral values of $m$ are evaluated as follows:

$$
\begin{aligned}
& A_{m n}=\frac{1}{2 \pi^{2}} \int_{-\pi / 2}^{3 \pi / 2} \int_{-\pi}^{\pi} h\left(\omega_{c} t, \omega t\right) \cos \left(m \omega_{c} t+n \omega t\right) d \omega_{c} t d \omega t \\
& B_{m n}=\frac{1}{2 \pi^{2}} \int_{-\pi / 2}^{3 \pi / 2} \int_{-\pi}^{\pi} h\left(\omega_{c} t, \omega t\right) \sin \left(m \omega_{c} t+n \omega t\right) d \omega_{c} t d \omega t .
\end{aligned}
$$

The coefficients of $A_{m n}$ and $B_{m n}$ can be expressed in the complex form as follows:

$$
\begin{array}{r}
C_{m n}=A_{m n}+j B_{m n}= \\
\frac{1}{2 \pi^{2}} \int_{-\pi / 2}^{3 \pi / 2} \int_{-\pi}^{\pi} h\left(\omega_{c} t, \omega t\right) e^{j\left(m \omega_{c} t+n \omega t\right)} d \omega_{c} t d \omega t .
\end{array}
$$

In Eq. (7), the first summation term, $A_{00} / 2$, corresponds to the DC component of the waveform. The second summation term, $\left(\sum_{n=1}^{\infty}\left[A_{0 n} \cos (n \omega t)+B_{0 n} \sin (n \omega t)\right]\right)$, corresponds to the 
fundamental and base-band harmonics. The third summation term, $\left(\sum_{m=1}^{\infty}\left[A_{m 0} \cos \left(m \omega_{c} t\right)+\right.\right.$ $\left.\left.B_{m 0} \sin \left(m \omega_{c} t\right)\right]\right)$, is the sum of carrier harmonics. The final summation term, $\left(\sum_{m=1}^{\infty}\right.$ $\left.\sum_{n=-\infty_{n \neq 0}}^{\infty}\left[A_{m n} \cos \left(m \omega_{c} t+n \omega t\right)+B_{m n} \sin \left(m \omega_{c} t+n \omega t\right)\right]\right)$, corresponds to the side-band harmonics (Holmes \& Lipo 2003).

\subsection{Unit cell}

The top-switch current $i_{R 1}$ is a function in $\omega_{c} t$ and $\omega t$ as mentioned earlier. Hence it can be defined in a two-dimensional space with $\omega_{c} t$ and $\omega t$ as the orthogonal axes. Furthermore, $i_{R 1}$ is periodic in both $\omega_{c} t$ and $\omega t$, with a periodicity of $2 \pi$. Hence one needs to consider only an interval of $2 \pi$ along each of the axes. Such a region bounded by one period of both variables is termed as unit cell. In this discussion, the unit cell is defined as the region formed by $-\pi<$ $\omega_{c} t<\pi$ and $-\pi / 2<\omega t<3 \pi / 2$ (see figure $5 \mathrm{a}$ and $\mathrm{b}$ ).

\subsection{Contour plot}

To evaluate the Double Fourier series coefficients $A_{m n}$ and $B_{m n}$, a double integration needs to be carried out as indicated by (5). However, if the PWM waveform has only discrete values (say high or low), then the unit cell can be divided into two (sets of) regions depending on the value of the waveform (Holmes \& Lipo 2003). The boundary separating the two regions is termed as contour plot (Holmes \& Lipo 2003). (More generally, the unit cell is divided into a number of regions, each corresponding to a particular value of the function). Such a method of analysis is called the 'geometric wall' method. This method is used for harmonic analysis of DC-link current in this work.

The top-switch current $i_{R 1}$ equals either $i_{R}$ or zero as mentioned earlier. Hence the unit cell gets divided into two regions, where $i_{R 1}=i_{R}$ and $i_{R 1}=0$. This division depends on the modulation scheme as discussed in the following sections.

\section{Harmonic analysis with sine-triangle PWM}

A few popular sine-triangle PWM schemes for an NPC inverter are briefly reviewed. The harmonic analysis of the DC link current, when the NPC inverter is modulated with the In-phase level-shifted sine triangle PWM, is discussed.

\subsection{Review of SPWM schemes}

From figure 1, it can be seen that there are four devices in each leg and switches SR1 and SR3 are complementary and SR2 and SR4 are complementary (Das 2013). Hence, two distinct PWM pulses are required to switch the devices in the leg. For generating the distinct PWM pulses using the SPWM scheme, the following methods can be adopted (Das 2013).

4.1a In-phase sine triangle PWM (IPSPWM): In this scheme, a sinusoidal modulating signal is compared against two level shifted carriers as shown in figure 4(a). Here, the positive carrier varies from 0 to 1 and the negative carrier varies from -1 to 0 . The switching pulses for the switches SR1 and SR3 is generated by comparison with the top carrier and the switching pulses for the switches SR2 and SR4 is generated by comparison with the bottom carrier. 
1510

Gopalakrishnan K S and G Narayanan

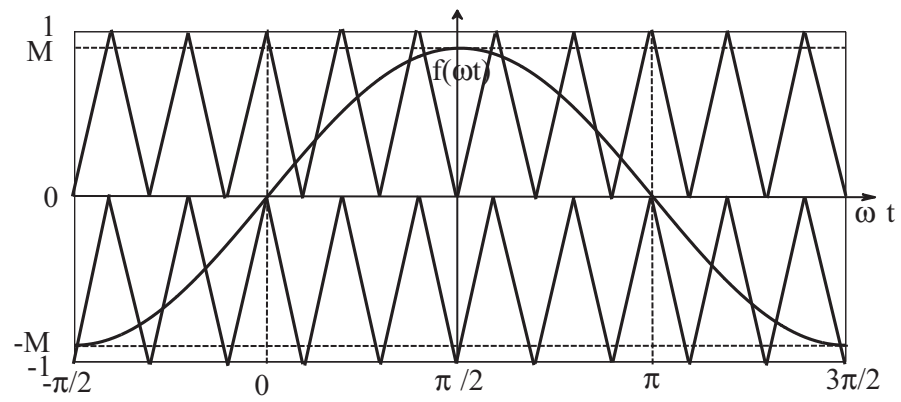

(a)

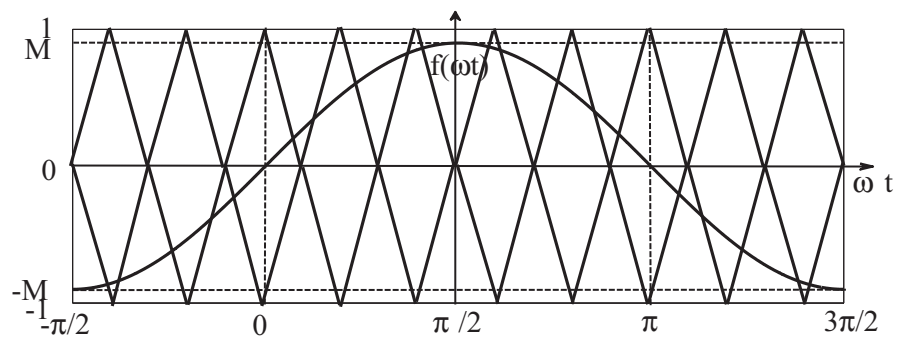

(b)

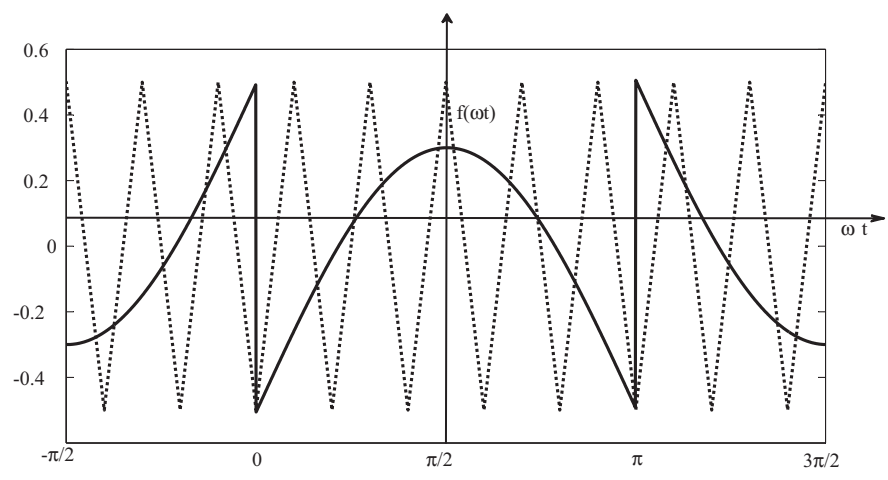

(c)

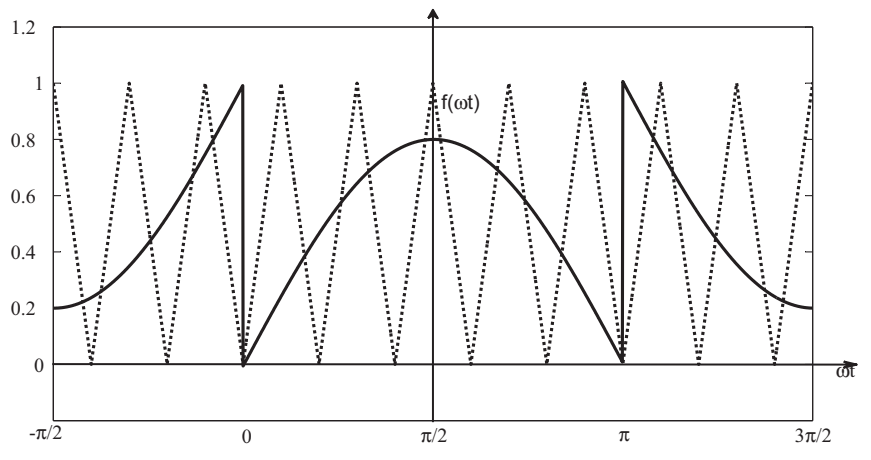

(d)

Figure 4. (a) IPSPWM. (b) POSPWM. (c) SBCSPWM. (d) SUCSPWM. 


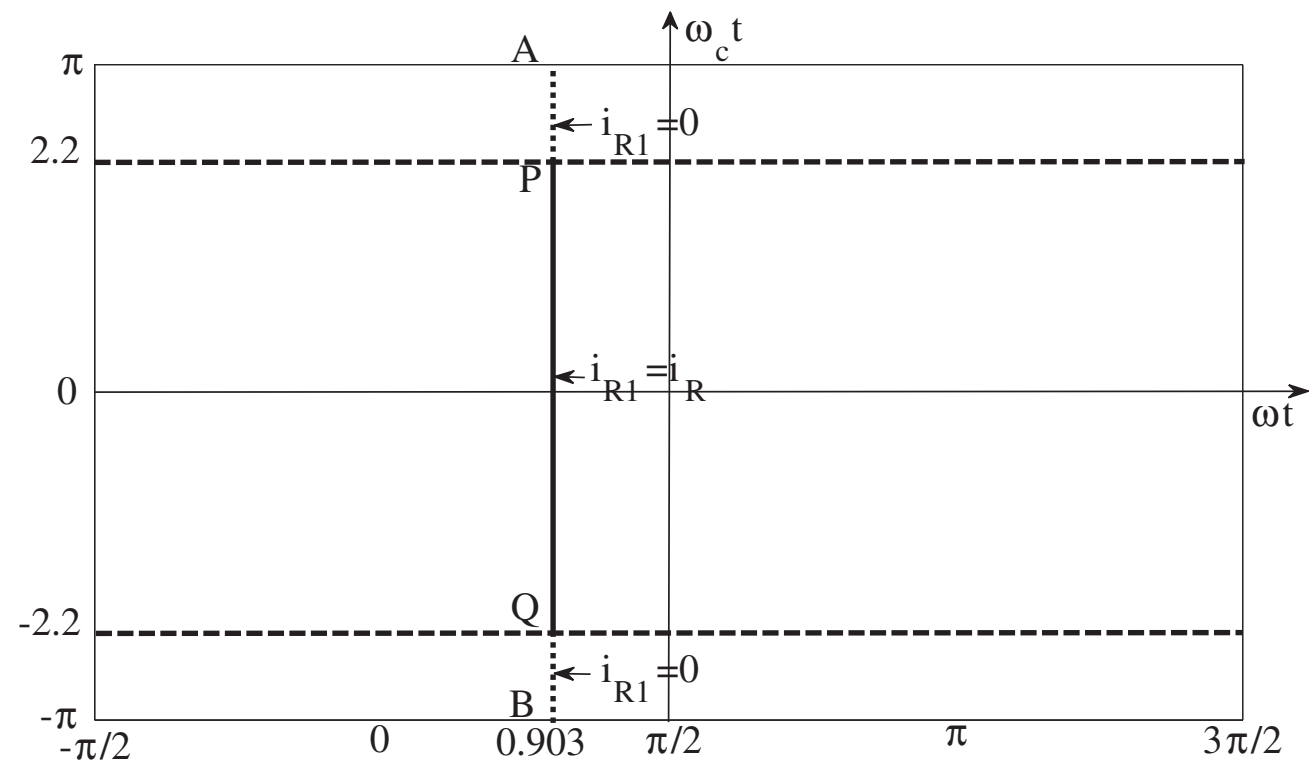

(a)

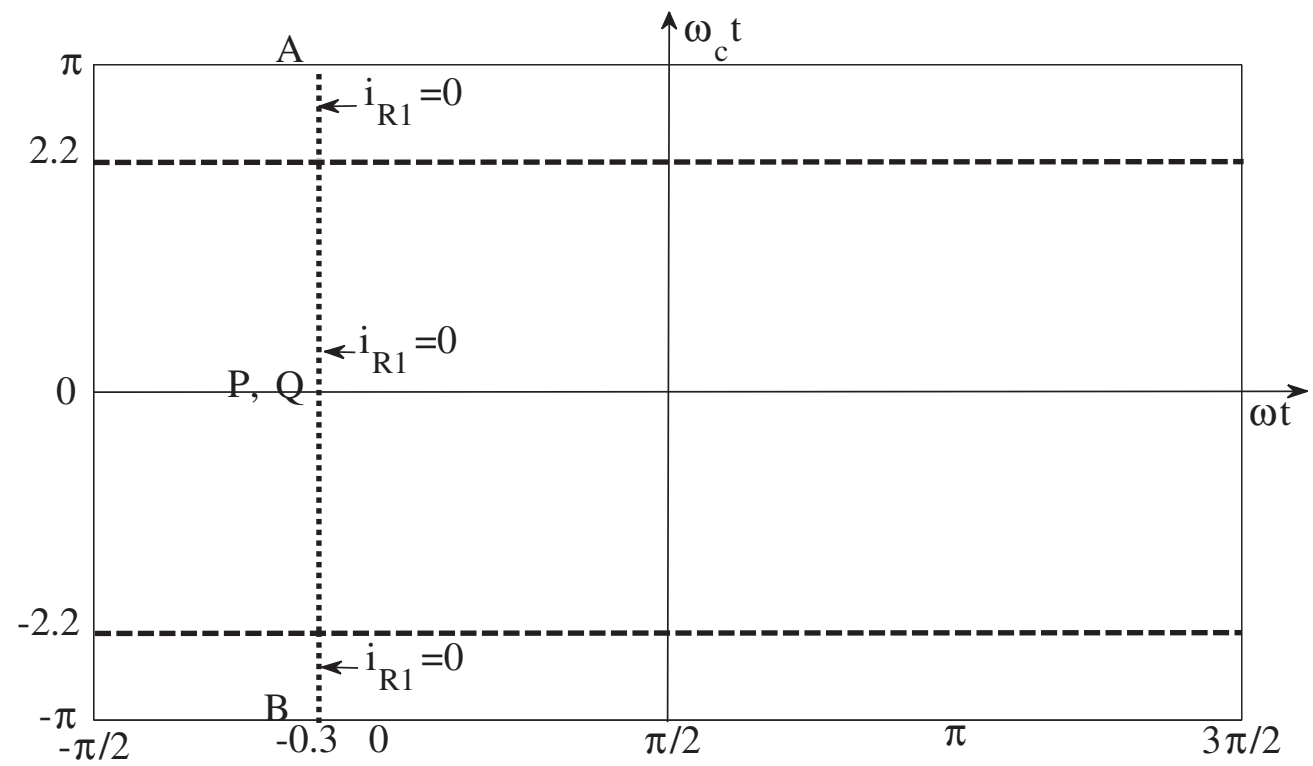

(b)

Figure 5. (a) Representation of the switching cycle, figure 3a in a unit cell (b) Representation of the switching cycle, figure $3 \mathrm{~b}$ in a unit cell. 
4.1b Phase-opposition sinusoidal pulse width modulation (POSPWM): In this switching scheme, the top and bottom carriers are phase shifted by $180^{\circ}$ as shown in figure 4 (b). But the harmonic content in the load current due to this scheme is much higher than IPSPWM scheme (Das 2013) and therefore is not widely used.

4.1c Single bipolar carrier sinusoidal PWM (SBCSPWM): In this switching scheme, the top carrier is offset by -0.5 and the bottom carrier is offset by +0.5 . Therefore, both the carriers merge into a single bi-polar carrier. The sinusoidal modulating signal is modified as shown in (10). Figure 4(c) shows the modified modulating signal and carrier signal in this scheme.

$$
\begin{aligned}
& f(\omega t)=f(\omega t)-0.5, \text { when } f(\omega t)>0 \\
& f(\omega t)=f(\omega t)+0.5, \text { when } f(\omega t)<0 .
\end{aligned}
$$

However, the PWM pulses produced using this scheme is same as the case in IPSPWM (Das 2013).

4.1d Single unipolar carrier sinusoidal PWM (SUCSPWM): In this switching scheme, there is only one carrier signal, varying from 0 to 1 . The sinusoidal modulating signal is modified as shown in (11). Figure 4(d) shows the modified modulating signal and carrier signal in this scheme.

$$
\begin{array}{r}
f(\omega t)=f(\omega t) \text { when } f(\omega t)>0 \\
f(\omega t)=f(\omega t)+1, \text { when } f(\omega t)<0 .
\end{array}
$$

The PWM pulses produced using this scheme is also the same as with IPSPWM (Das 2013). After comparing all these SPWM schemes, IPSPWM scheme was chosen for harmonic analysis as it is the most widely used scheme and produces the least Total harmonic distortion (THD) in the load current (Das 2013).

\subsection{Modulation signal for IPSPWM scheme}

The three legs are switched by comparing three-phase sinusoidal modulating signals against two level-shifted, in-phase, triangular carriers as illustrated in figure 4. The R-phase modulating wave $f(\omega t)$, the top carrier wave $g_{1}\left(\omega_{c} t\right)$, and the bottom carrier wave $g_{2}\left(\omega_{c} t\right)$ are described mathematically in (12), where $M$ is the modulation index; $\omega_{c}$ is the carrier angular frequency; $\omega$ is the fundamental angular frequency.

$$
\begin{aligned}
f(\omega t) & =M \sin (\omega t) & & \frac{-\pi}{2}<\omega t<\frac{3 \pi}{2} \\
g_{1}\left(\omega_{c} t\right) & =-\omega_{c} t / \pi & & -\pi<\omega_{c} t<0 \\
g_{1}\left(\omega_{c} t\right) & =\omega_{c} t / \pi & & 0<\omega_{c} t<\pi \\
g_{2}\left(\omega_{c} t\right) & =-1-\omega_{c} t / \pi & & -\pi<\omega_{c} t<0 \\
g_{2}\left(\omega_{c} t\right) & =-1+\omega_{c} t / \pi & & 0<\omega_{c} t<\pi .
\end{aligned}
$$

\subsection{Contour plot}

Consider the switching cycle in figure $3 \mathrm{a}$. It can be represented by a vertical line AB (i.e. $\omega t=$ $52^{\circ}=0.903 \mathrm{rad}$ ) in the unit cell as shown in figure 5a. The line segment PQ represents the 
duration for which $i_{R 1}=i_{R}$ within this switching cycle. Furthermore, the segments BQ and AP represent the intervals when $i_{R 1}=0$ at the start and end of the switching cycle, respectively.

The switching cycle in figure $3 \mathrm{~b}$, can be represented by a vertical line $\mathrm{AB}$ (i.e. $\omega t=-0.3$ $\mathrm{rad}$ ) in the unit cell, as shown shown in figure 5b. Since $i_{R 1}=0$ in the entire duration of the sub cycle, the line segment PQ is of zero length as seen from figure $5 b$. Both these points $\mathrm{P}$ and $\mathrm{Q}$ coincide with each other, and lie on the horizontal axis in figure $5 \mathrm{~b}$.

The loci of the points $\mathrm{P}$ and $\mathrm{Q}$ represent the boundary separating the regions where $i_{R 1}=0$ and $i_{R 1}=i_{R}$. If the modulation signal is a sine wave (as in SPWM), the loci of the points $\mathrm{P}$ and $\mathrm{Q}$ yield the contour plot of $i_{R 1}$ shown in figure 6. From figure 6, it can be seen that the current $i_{R 1}=i_{R}$ in the region $\pi M \sin (\omega t)<\omega_{c} t<-\pi M \sin (\omega t)$ and $0<\omega t<\pi$. In all the other regions, $i_{R 1}=0$.

\subsection{Evaluation of harmonic components}

The harmonic components of the current $i_{R 1}$ can be found by applying double Fourier integral on the function (i.e. $i_{R 1}$ ) in the unit cell. This integral returns a zero value in all the regions except the region $-\pi M \sin (\omega t)<\omega_{c} t<\pi M \sin (\omega t)$, where the function assumes the value $i_{R}$. This reduced integral is given in (13). The harmonic components of currents $i_{Y 1}^{m n}$ and $i_{B 1}^{m n}$ are obtained from (13), by multiplying the same by $e^{2 j n \pi / 3}$ and $e^{-2 j n \pi / 3}$, respectively, as shown in (14) and (15).

$$
\begin{gathered}
i_{R 1}^{m n}=\frac{1}{2 \pi^{2}} \int_{0}^{\pi} \int_{-\pi M \sin \omega t}^{\pi M \sin \omega t} i_{R} e^{j\left(m \omega_{c} t+n \omega t\right)} d \omega_{c} t d \omega t \\
i_{Y 1}^{m n}=\frac{1}{2 \pi^{2}} \int_{0}^{\pi} \int_{-\pi M \sin \omega t}^{\pi M \sin \omega t} i_{R} e^{j\left(m \omega_{c} t+n \omega t\right)} d \omega_{c} t d \omega t e^{j(2 n \pi / 3)}
\end{gathered}
$$

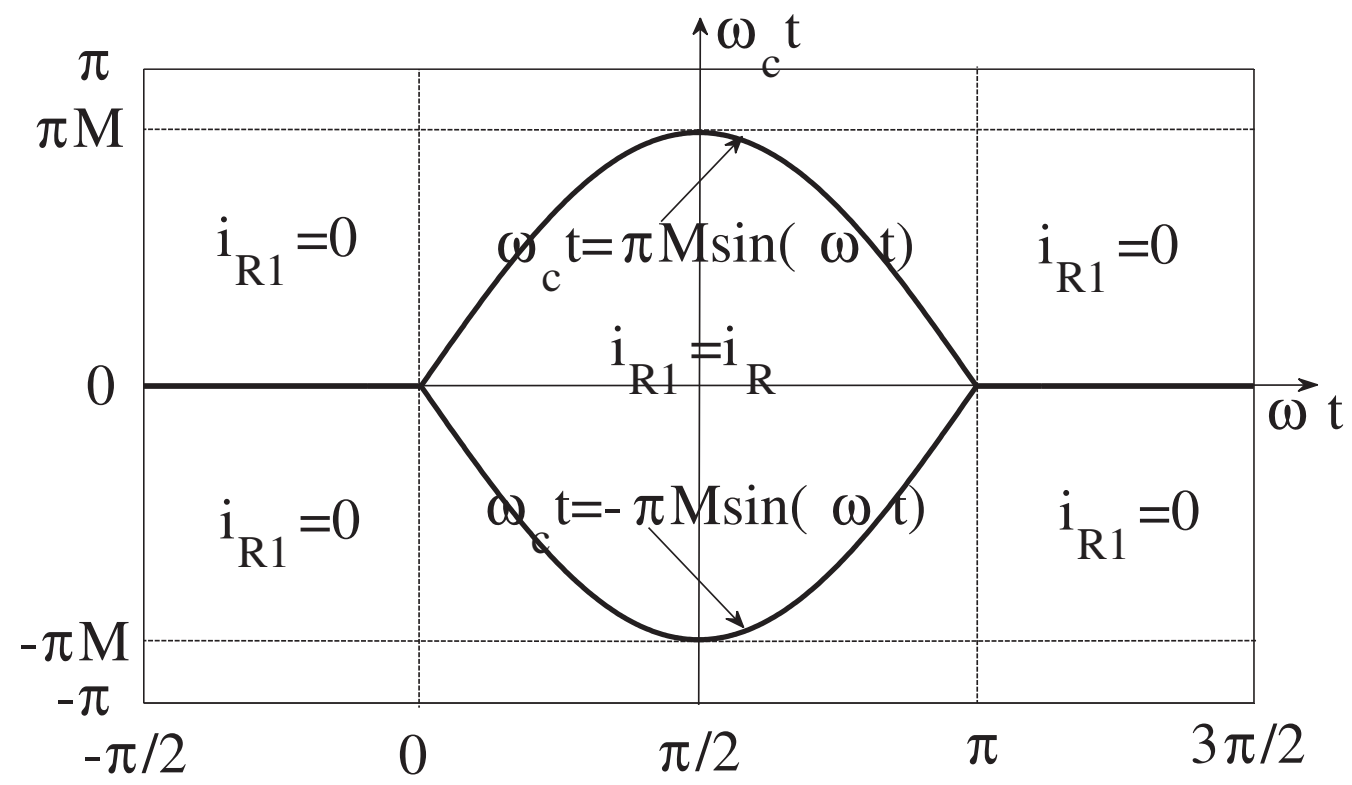

Figure 6. Contour plot of $i_{R 1}$. 


$$
\begin{gathered}
i_{B 1}^{m n}=\frac{1}{2 \pi^{2}} \int_{0}^{\pi} \int_{-\pi M \sin \omega t}^{\pi M \sin \omega t} i_{R} e^{j\left(m \omega_{c} t+n \omega t\right)} d \omega_{c} t d \omega t e^{-j(2 n \pi / 3)} \\
i_{1}^{m n}=i_{R 1}^{m n}+i_{Y 1}^{m n}+i_{B 1}^{m n} .
\end{gathered}
$$

The harmonic components of the DC-link current $i_{1}$ are obtained by summing the respective components of $i_{R 1}, i_{Y 1}$ and $i_{B 1}$ as indicated by (16). The harmonic components are calculated using (13) - (16). A MATLAB code is written for the purpose.

\section{Harmonic analysis with conventional space-vector PWM}

The functions $g_{1}\left(\omega_{c} t\right)$ and $g_{2}\left(\omega_{c} t\right)$, which are the carrier signals, remain the same here. The function $f(\omega t)$ which is the modulating signal for CSVPWM varies with modulation index (Lee et al 2000; Wang 2002).

\subsection{Modulating signals}

The equations of the modulating signal in the three ranges of modulation indices, namely $0.667<M<1.15,0.577<M<0.667$ and $0<M<0.577$, are given in table 3 , table 4 and table 5 , respectively. Here, on account of half-wave symmetry, the modulation signal is defined over one half cycle only (i.e. 0 to $\pi$ radians). The expression for modulation signal is different in the different intervals of the half cycle. Each of these intervals is defined by the starting angle $\theta_{1}$ and ending angle $\theta_{2}$ in tables $3-4$.

Table 3. Expression for R-phase modulating signals for modulation index $0.667<M<1.15$.

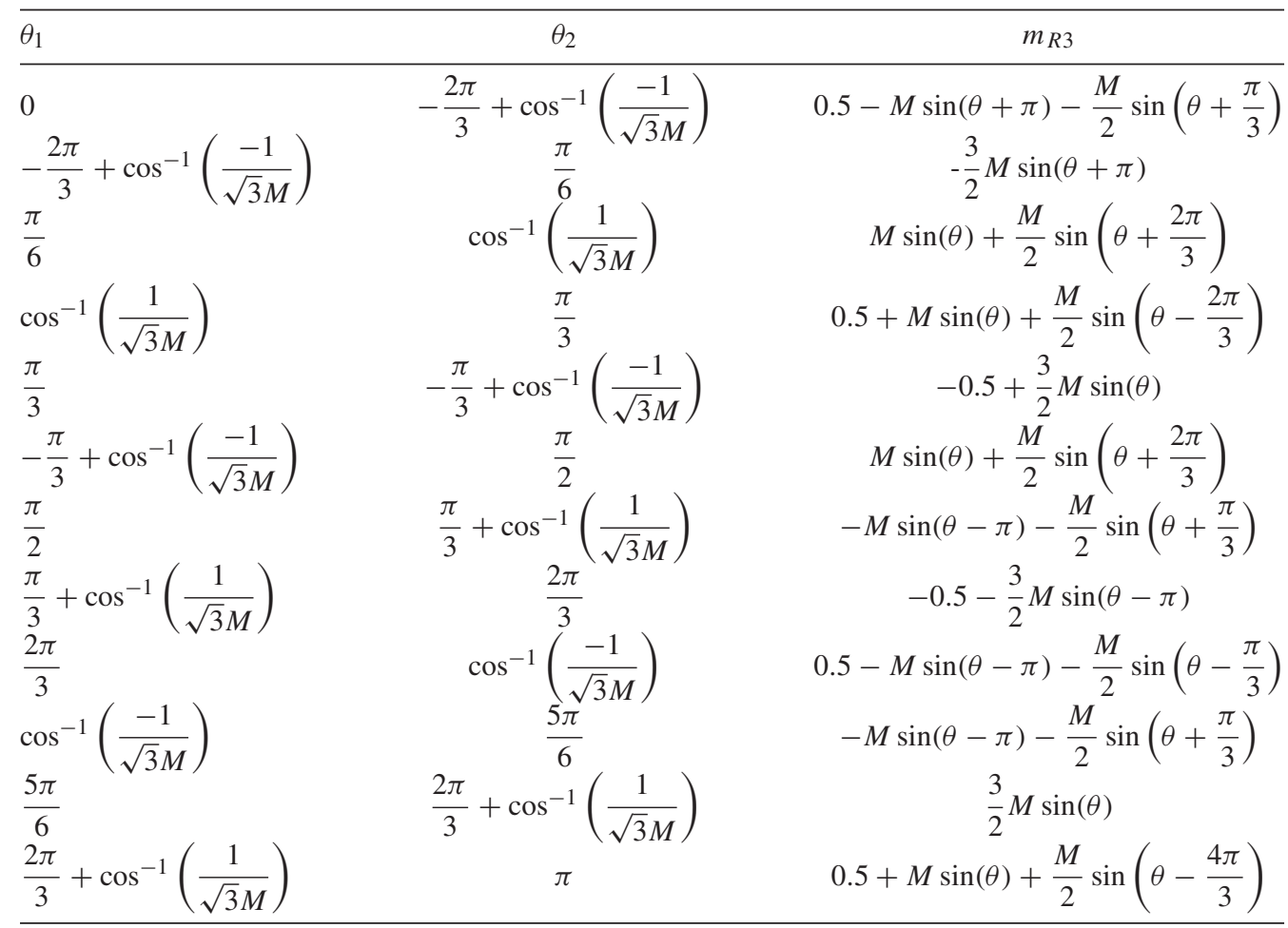


Table 4. Expression for R-phase modulating wave for modulation index $0.577<M<0.667$.

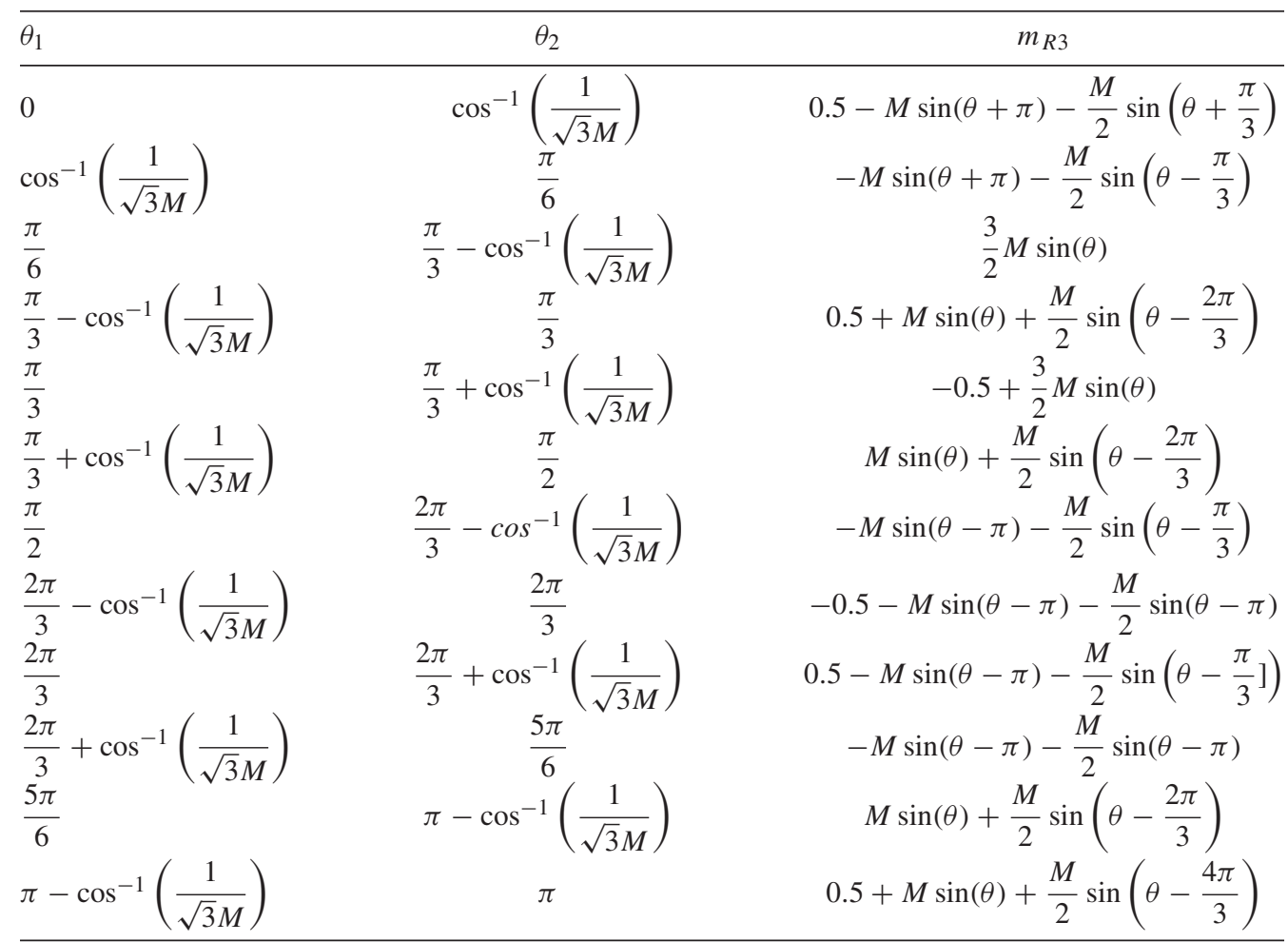

The modulating signal in the range $0.667<M<1.15$ consists of 12 different regions in one half of the fundamental cycle as seen from table 3 . The modulation signal for $M=0.9$ in this region is shown plotted in figure 7(a). The modulation signal for $M=0.4$ is plotted in figure 7 (b). In the modulation index range $0<M<0.577$, the half cycle is divided into six regions. The expression for the modulation signal in each of these six regions is shown in table 5. The modulation signal for $M=0.6$ is shown plotted in figure 7(c).

Table 5. Expression for R-phase modulating wave for modulation index $0<M<0.577$.

\begin{tabular}{lcc}
\hline$\theta_{1}$ & $\theta_{2}$ & $m_{R 3}$ \\
\hline 0 & $\frac{\pi}{6}$ & $-M \sin (\theta+\pi)-\frac{M}{2} \sin \left(\theta-\frac{\pi}{3}\right)$ \\
$\frac{\pi}{6}$ & $\frac{\pi}{3}$ & $\frac{3}{2} M \sin (\theta)$ \\
$\frac{\pi}{3}$ & $\frac{\pi}{2}$ & $M \sin (\theta)+\frac{M}{2} \sin \left(\theta-\frac{2 \pi}{3}\right)$ \\
$\frac{\pi}{2}$ & $\frac{2 \pi}{3}$ & $-M \sin (\theta-\pi)-\frac{M}{2} \sin \left(\theta-\frac{2 \pi}{3}\right)$ \\
$\frac{2 \pi}{3}$ & $\frac{5 \pi}{6}$ & $-M \sin (\theta-\pi)-\frac{M}{2} \sin (\theta-\pi)$ \\
$\frac{5 \pi}{6}$ & $\pi$ & $M \sin (\theta)+\frac{M}{2} \sin \left(\theta-\frac{2 \pi}{3}\right)$ \\
\hline
\end{tabular}




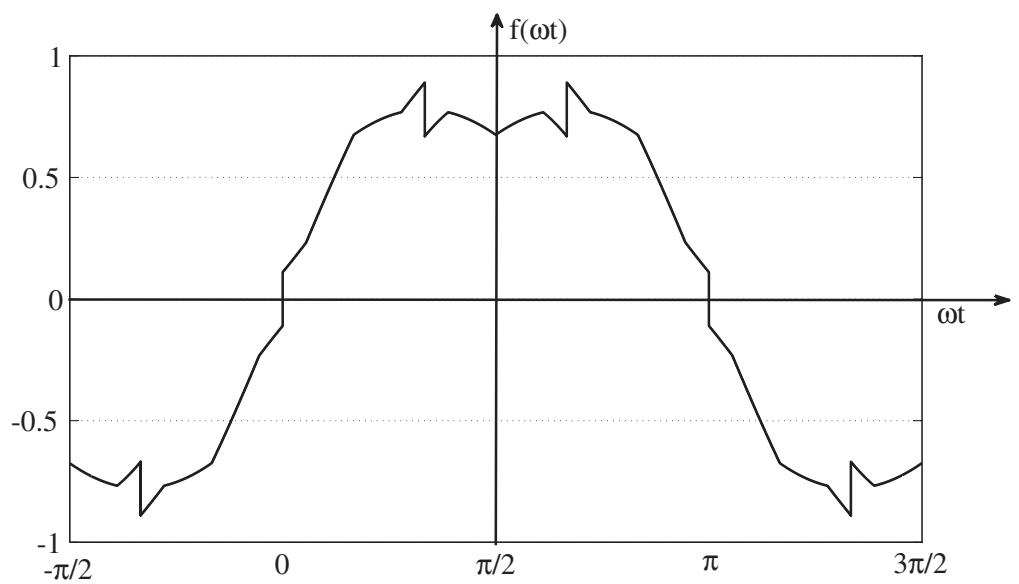

(a)

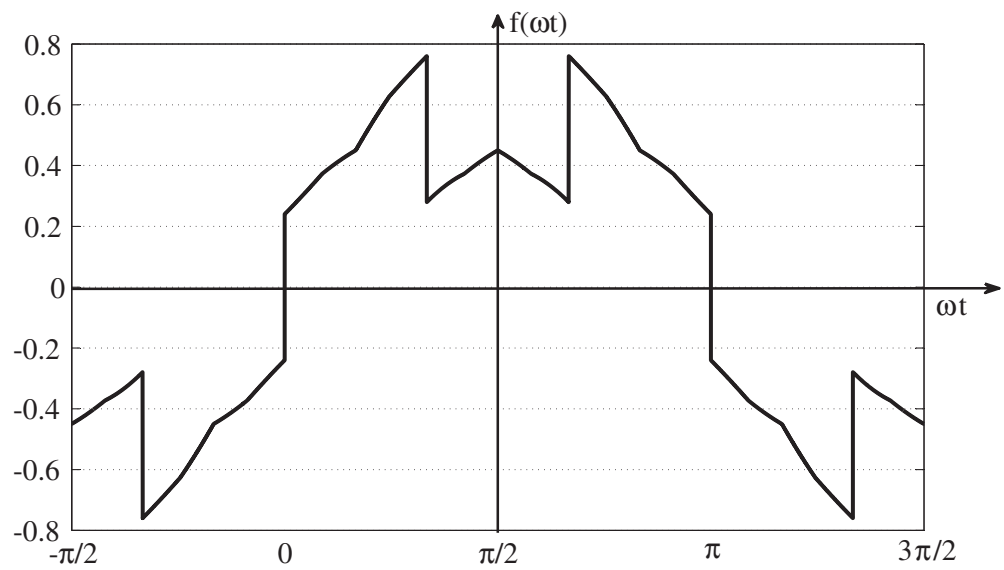

(b)

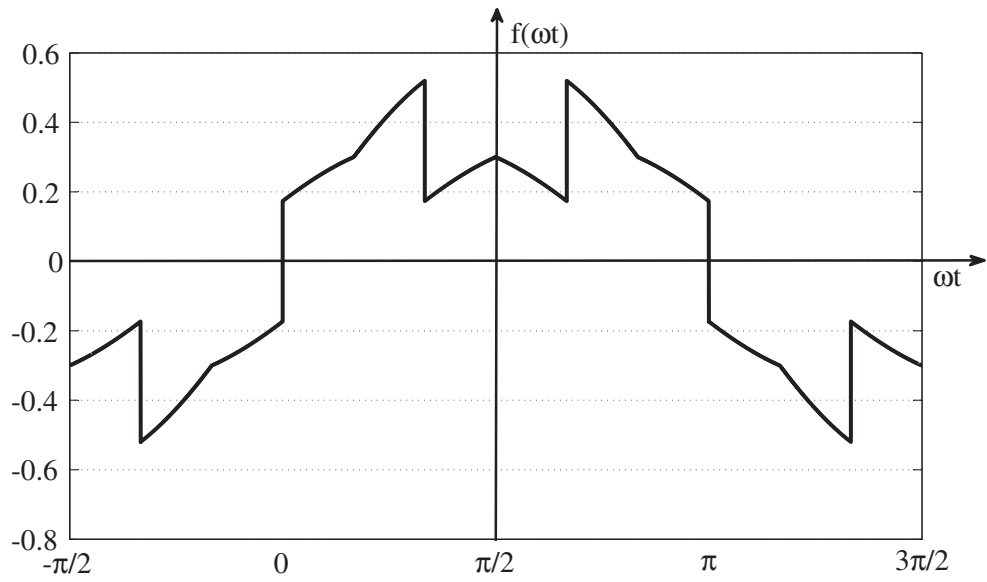

(c)

Figure 7. Modulation signal for CSVPWM for (a) $M=0.9$ (b) $M=0.6$ (c) $M=0.4$. 


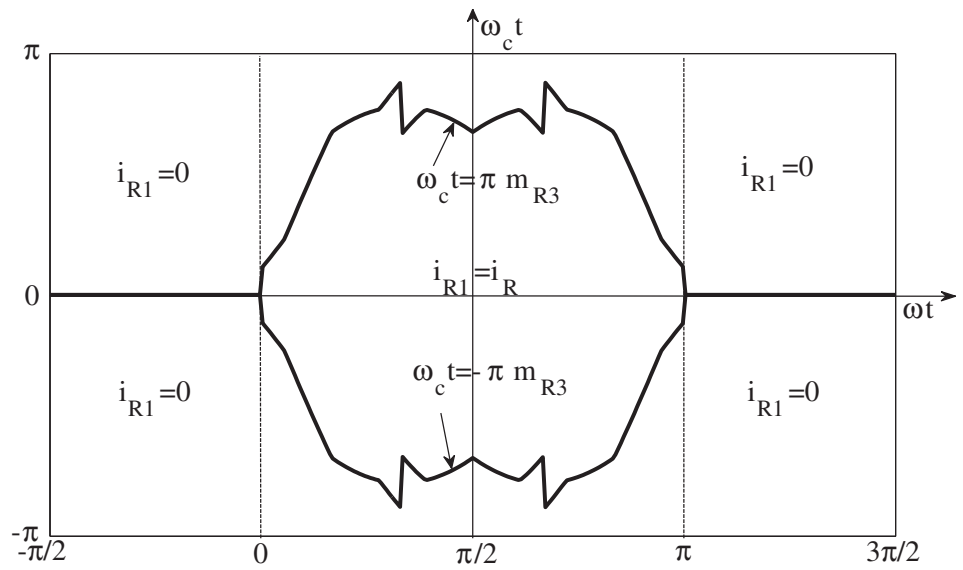

(a)

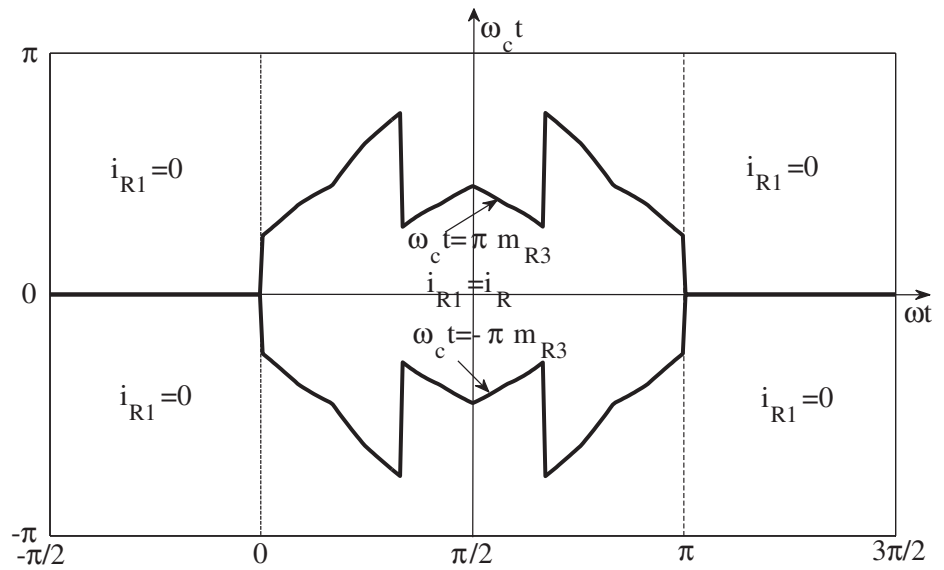

(b)

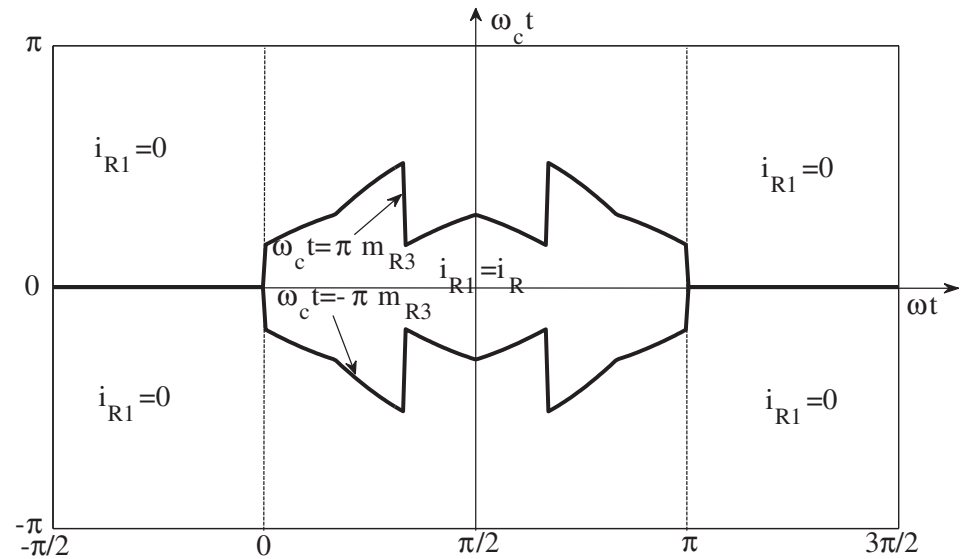

(c)

Figure 8. Contour plot of $i_{R 1}$ for CSVPWM at (a) $M=0.9$; (b) $M=0.6$; (c) $M=0.4$. 


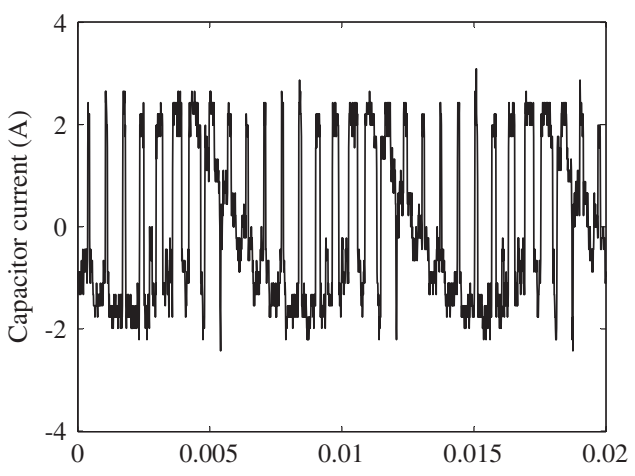

(a)

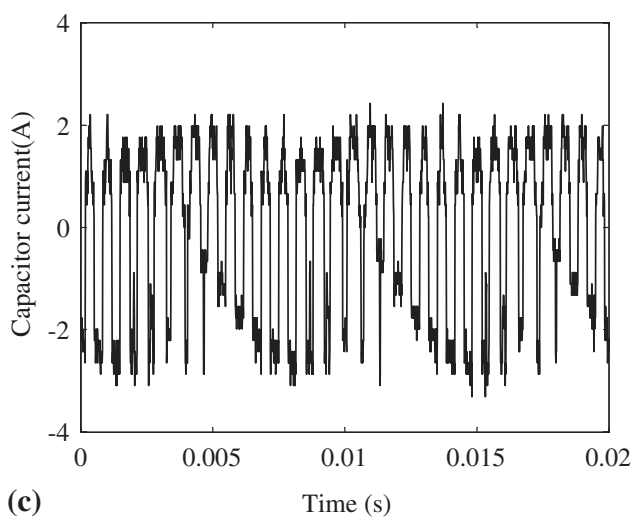

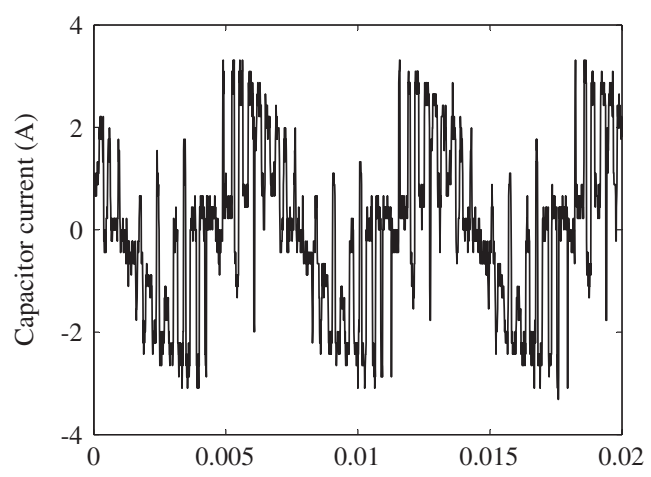

(b)

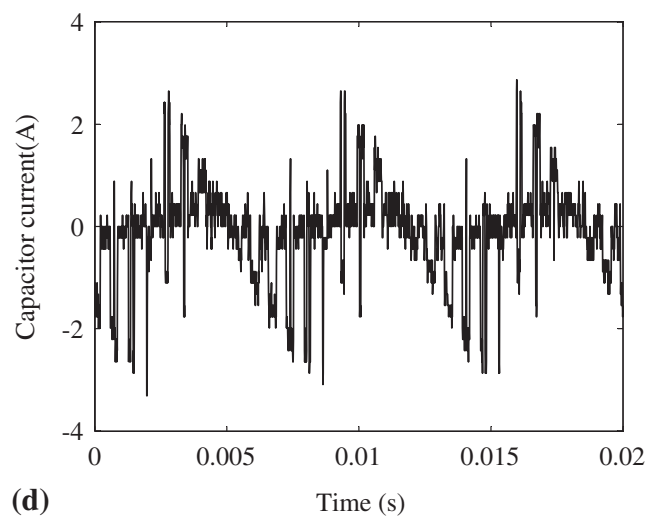

Figure 9. Measured DC-capacitor current waveform with SPWM scheme (a) $M=0.9, \cos (\phi)=$ 0.844 (lag); (b) $M=0.9, \cos (\phi)=0.137$ (lag); (c) $M=0.5, \cos (\phi)=0.844$ (lag); (d) $M=0.5, \cos (\phi)=$ 0.137 (lag).

\subsection{Contour plots}

A contour plot of the current $i_{R 1}$ in the unit cell is given in figure 8(a). It is plotted for modulation index $M=0.9$. As is the case with SPWM, the top device current is zero in all the regions except in the region $-\pi m_{R 3}<\omega_{c} t<\pi m_{R 3}$ and $0<\omega t<\pi$. Therefore the integration returns a non-zero value only in this region.

Similarly, a contour plot of the current $i_{R 1}$ for another modulation index of 0.6 is illustrated in figure 8(b). In this plot also it can be seen that the contour plot has a shape similar to that of the modulation function [figure 7(b)] in the region $0<\omega t<\pi$. The current $i_{R 1}$ is equal to $i_{R}$ in the region $-\pi m_{R 3}<\omega_{c} t<\pi m_{R 3}$ and $0<\omega t<\pi$. In all other regions of $\omega_{c} \mathrm{t}, i_{R 1}$ assumes a value of zero.

Another contour plot of the current $i_{R 1}$ for $M=0.4$ is given in figure 8(c). Once again, the regions where $i_{R 1}=i_{R}$ and $i_{R 1}=0$ are separated by boundaries whose shapes are similar to that of the modulation function in figure 7 (c). 


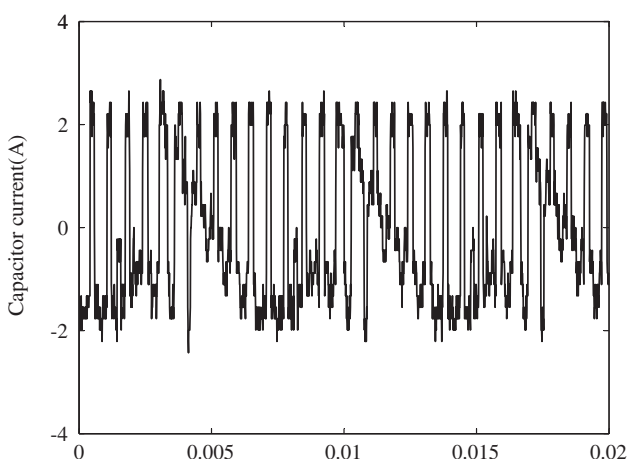

(a)

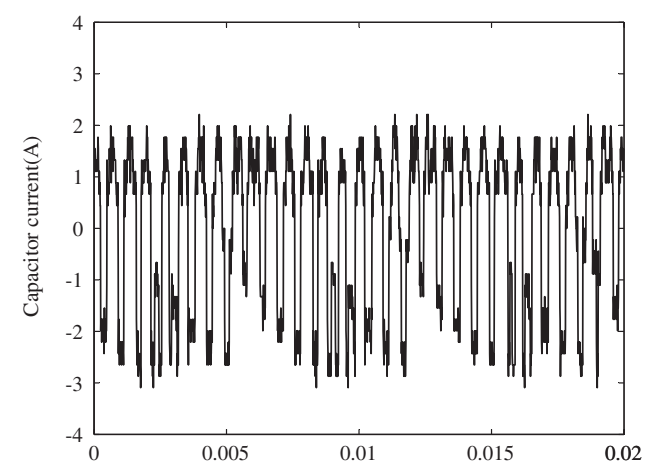

(c)

Time (s)

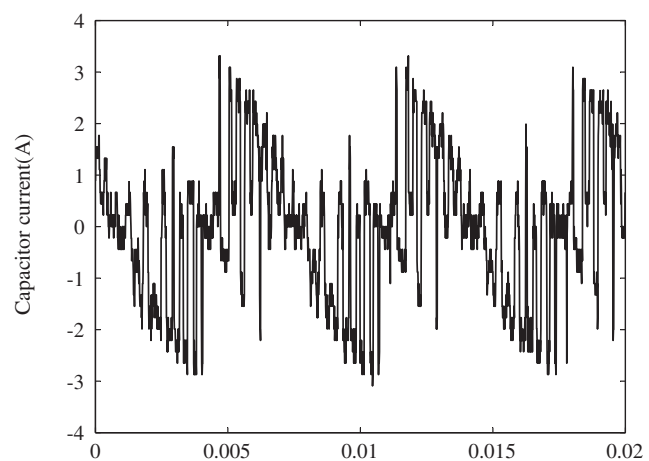

(b)

Time (s)

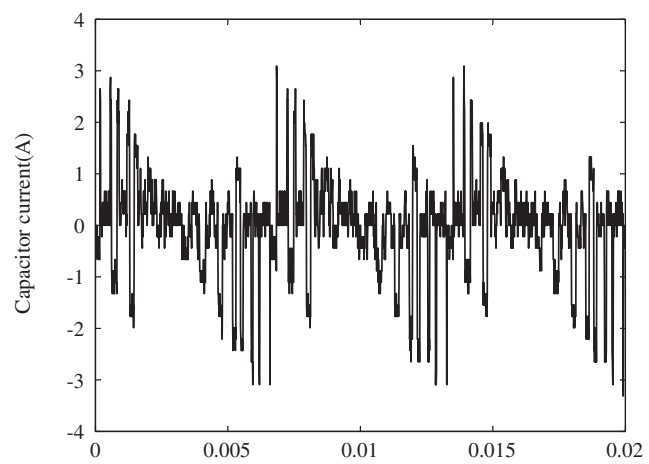

(d)

Figure 10. Measured DC-capacitor current waveform with CSVPWM scheme: (a) $M=0.9, \cos (\phi)=$ 0.844 (lag); (b) $M=0.9, \cos (\phi)=0.137$ (lag); (c) $M=0.5, \cos (\phi)=0.844($ lag); (d) $M=0.5, \cos (\phi)=$ 0.137 (lag).

\subsection{Evaluation of harmonic components}

The simplified double fourier integral equation for current $i_{R 1}$ in the region $0.667<M<1.15$ is given in (17). The expressions for the variables $m_{R 3}, \theta_{1}$ and $\theta_{2}$ in (17) are given in table 3 . The DC-link current harmonics are obtained using the Eqs. (14)-(16).

$$
i_{R 1}^{m n}=\frac{1}{2 \pi^{2}} \sum_{i=1}^{i=12} \int_{\theta_{1}(i)}^{\theta_{2}(i)} \int_{-\pi m_{R 3}}^{\pi m_{R 3}} i_{R} e^{j\left(m \omega_{c} t+n \omega t\right)} d \omega_{c} t d \omega t ; 0.666<M<1.15 .
$$

Similarly, the double fourier integral of the top switch current $\left(i_{R 1}\right)$ in the region $0.577<$ $M<0.667$ can be obtained using (18) and the expressions for $\theta_{1}, \theta_{2}$ and $m_{R 3}$ in table 4 .

$$
i_{R 1}^{m n}=\frac{1}{2 \pi^{2}} \sum_{i=1}^{i=12} \int_{\left.\theta_{1}(i)\right)}^{\left.\theta_{2}(i)\right)} \int_{-\pi m_{R 3}}^{\pi m_{R 3}} i_{R} e^{j\left(m \omega_{c} t+n \omega t\right)} d \omega_{c} t d \omega t ; 0.577<M<0.666 .
$$

A similar procedure is followed for evaluating the harmonic components of the current $\left(i_{R 1}\right)$ in the range $0<M<0.577$ as indicated by (19). In this case, there are only six regions in a half 


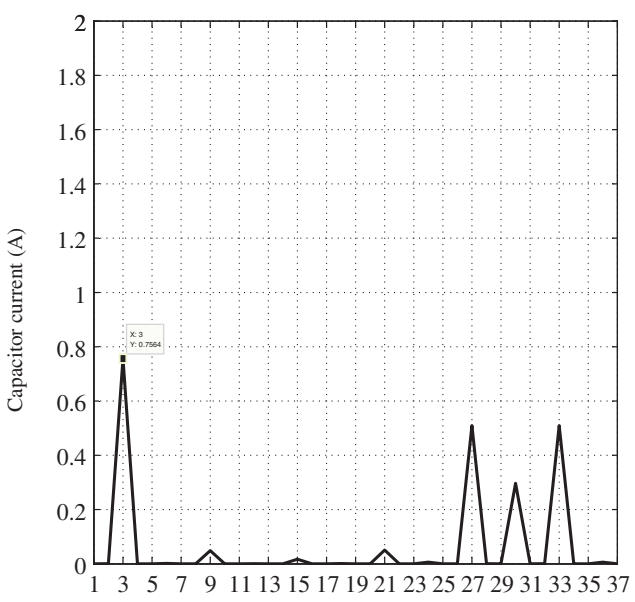

(a)

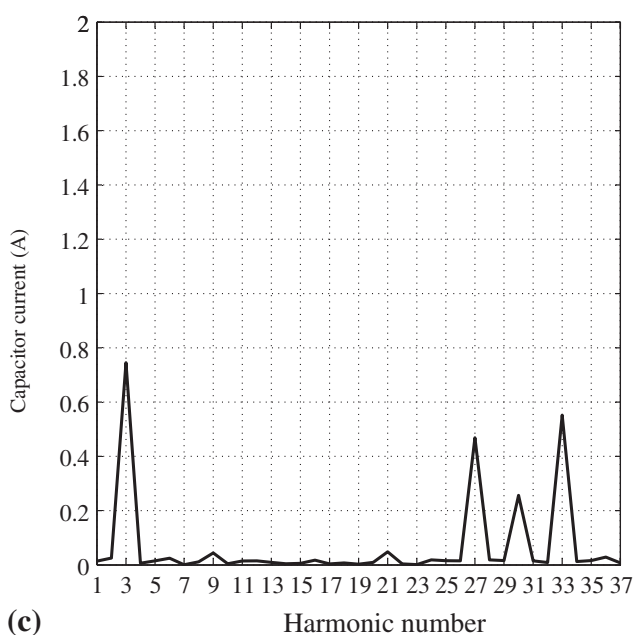

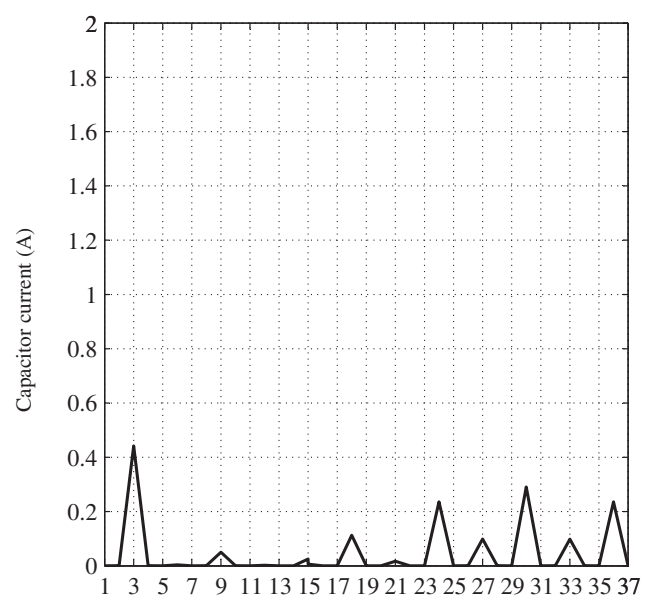

(b)

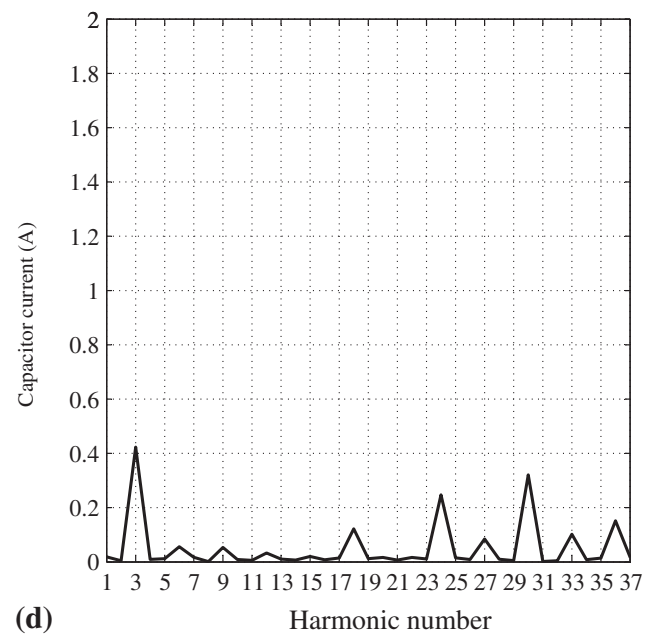

Figure 11. Analytical evaluated harmonic spectra of capacitor current for $M=0.5$ and $\cos (\phi)=$ 0.137(lag) for (a) SPWM scheme; (b) CSVPWM scheme. Experimentally obtained harmonic spectrum of capacitor current waveform at $M=0.5$ and $\cos (\phi)=0.137$ (lag) (c) SPWM scheme; (d) CSVPWM scheme.

cycle instead of twelve as in the earlier cases. The expressions for $\theta_{1}, \theta_{2}$ and $m_{R 3}$ in the six regions are given in table 5 .

$$
i_{R 1}^{m n}=\frac{1}{2 \pi^{2}} \sum_{i=1}^{i=6} \int_{\theta_{1}(i)}^{\theta_{2}(i)} \int_{-\pi m_{R 3}}^{\pi m_{R 3}} i_{R} e^{j\left(m \omega_{c} t+n \omega t\right)} d \omega_{c} t d \omega t ; 0<M<0.577 .
$$

\section{Analytical and experimental results}

The experimental setup consists of an IGBT based $3 \mathrm{kVA}$ inverter. The controller platform is TMS320LF2407A DSP processor. The switching frequency is $1.5 \mathrm{kHz}$. The load is a three-phase 

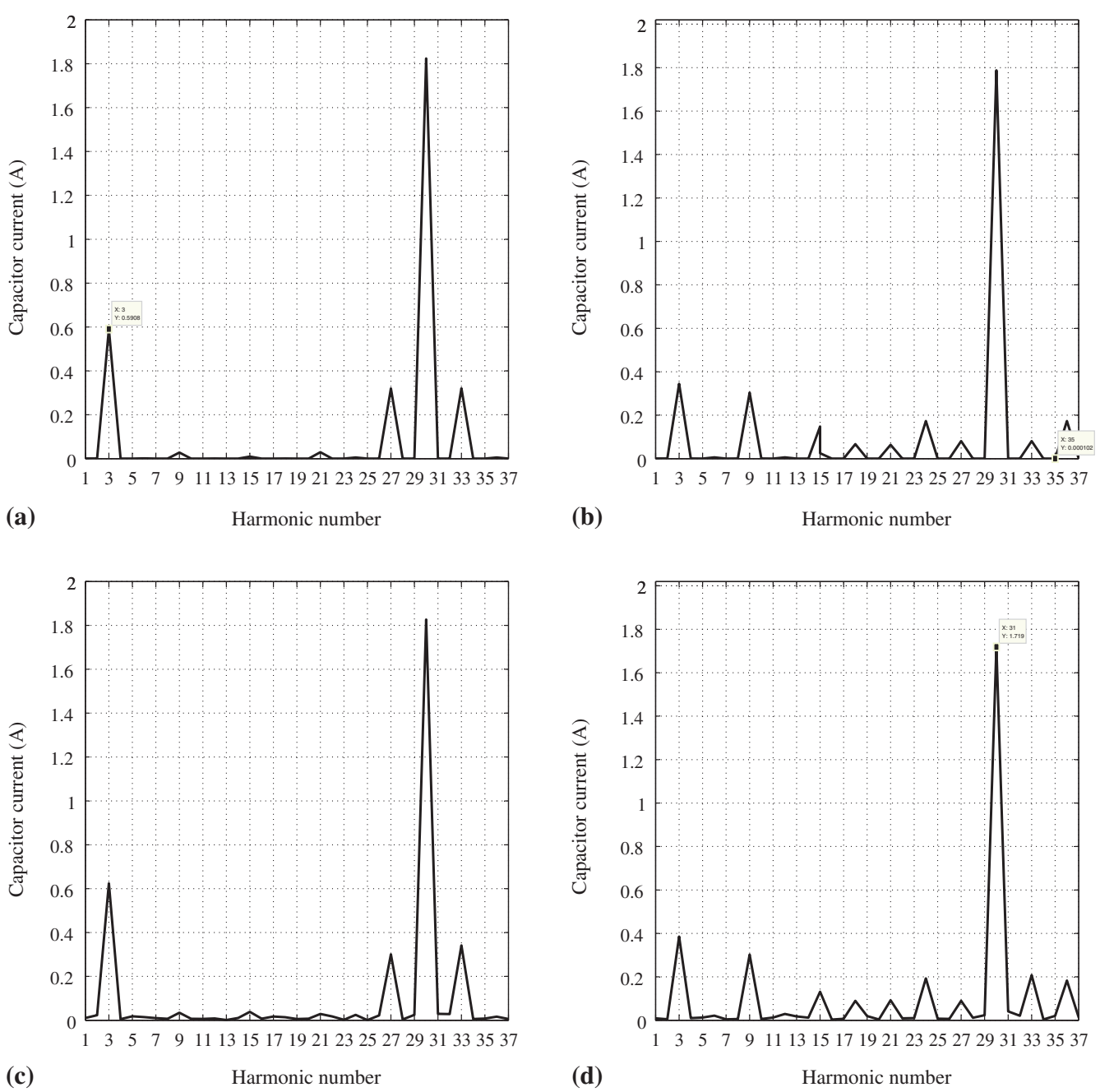

Figure 12. Analytical evaluated harmonic spectra of capacitor current for $M=0.5$ and $\cos (\phi)=$ 0.844(lag) for (a) SPWM scheme; (b) CSVPWM scheme. Experimentally obtained harmonic spectrum of capacitor current waveform at $M=0.5$ and $\cos (\phi)=0.844$ (lag); (c) SPWM scheme; (d) CSVPWM scheme.

R-L load. The per-phase inductance of the load is $10 \mathrm{mH}$. The power factor of the load is varied by changing the resistance of a rheostat in all the three phases of the load. The load current is kept constant at $4 \mathrm{~A}$, by varying the DC bus voltage appropriately. The capacitor current is measured using a fluke-1400S probe. Harmonic analysis of the measured capacitor current is done on MATLAB platform.

The measured capacitor currents with SPWM scheme at lagging power factors of 0.844 and 0.137 are given in figure 9(a) and figure 9(b), respectively, both at a modulation index of 0.9. Measured capacitor currents with SPWM scheme at a different modulation index of 0.5 , but at the same power factors of 0.844 and 0.137 are given in figure 9(c) and figure 9(d), respectively. 


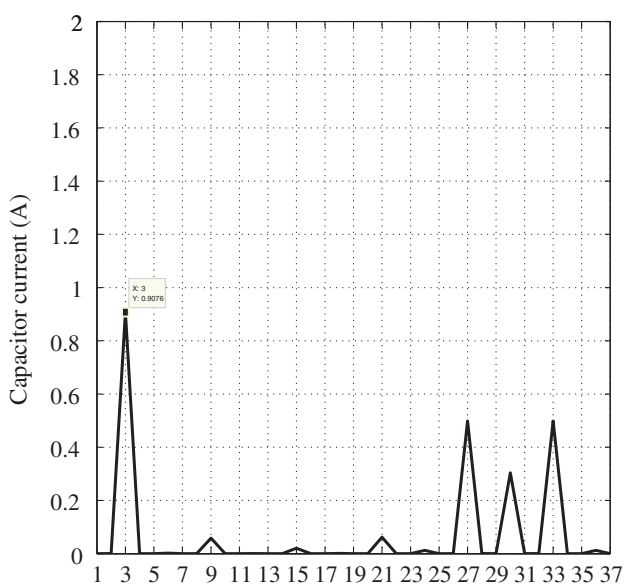

(a)

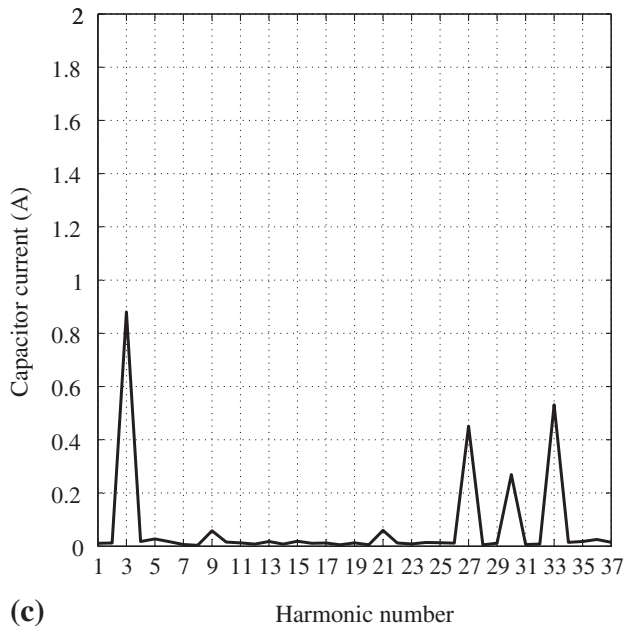

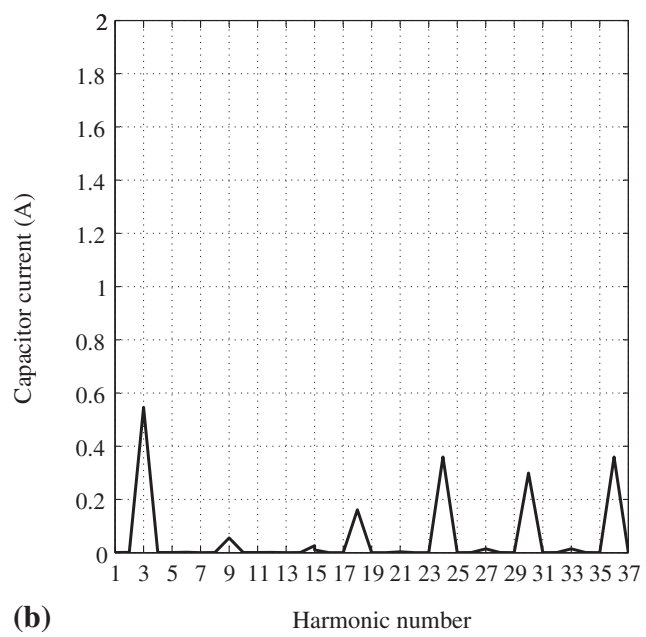

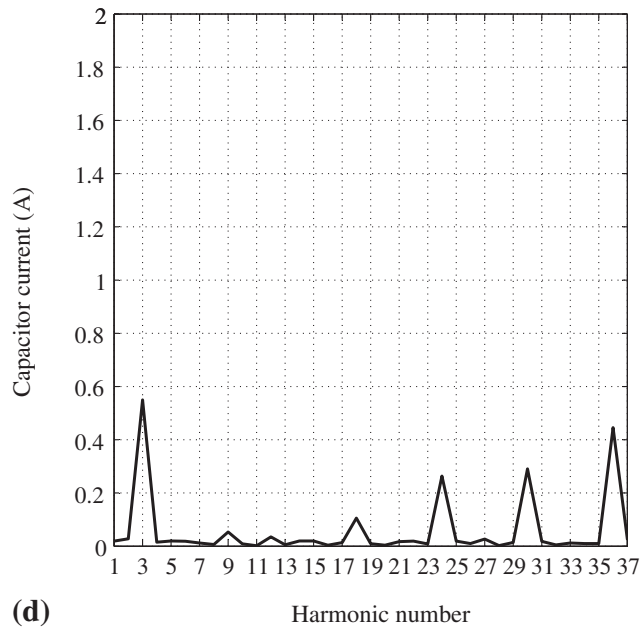

Figure 13. Analytical evaluated harmonic spectra of capacitor current for $M=0.6$ and $\cos (\phi)=$ 0.137 (lag) for (a) SPWM scheme; (b) CSVPWM scheme. Experimentally obtained harmonic spectrum of capacitor current waveform at $M=0.6$ and $\cos (\phi)=0.137$ (lag); (c) SPWM scheme; (d) CSVPWM scheme.

Figure 10(a)-(d) present the measured capacitor current waveforms with CSVPWM. The operating conditions pertaining to figure 10(a), figure 10(b), figure 10(c) and figure 10(d) are same as those of figure 9(a), figure 9(d), figure 9(c) and figure 9(d), respectively.

The analytical and experimental harmonic spectra of capacitor current are presented for three different modulation indices, namely $0.5,0.6$ and 0.9 . These correspond to the three ranges of modulation indices, namely $0<M<0.577,0.577<M<0.667$ and $0.667<M<1.15$. At each modulation index, one low power factor [i.e. 0.137 (lag)] and a high power factor [i.e. 0.844 (lag)] are considered. The analytical and measured spectra pertaining to SPWM and CSVPWM, for each combination of modulation index and power factor, are presented in 

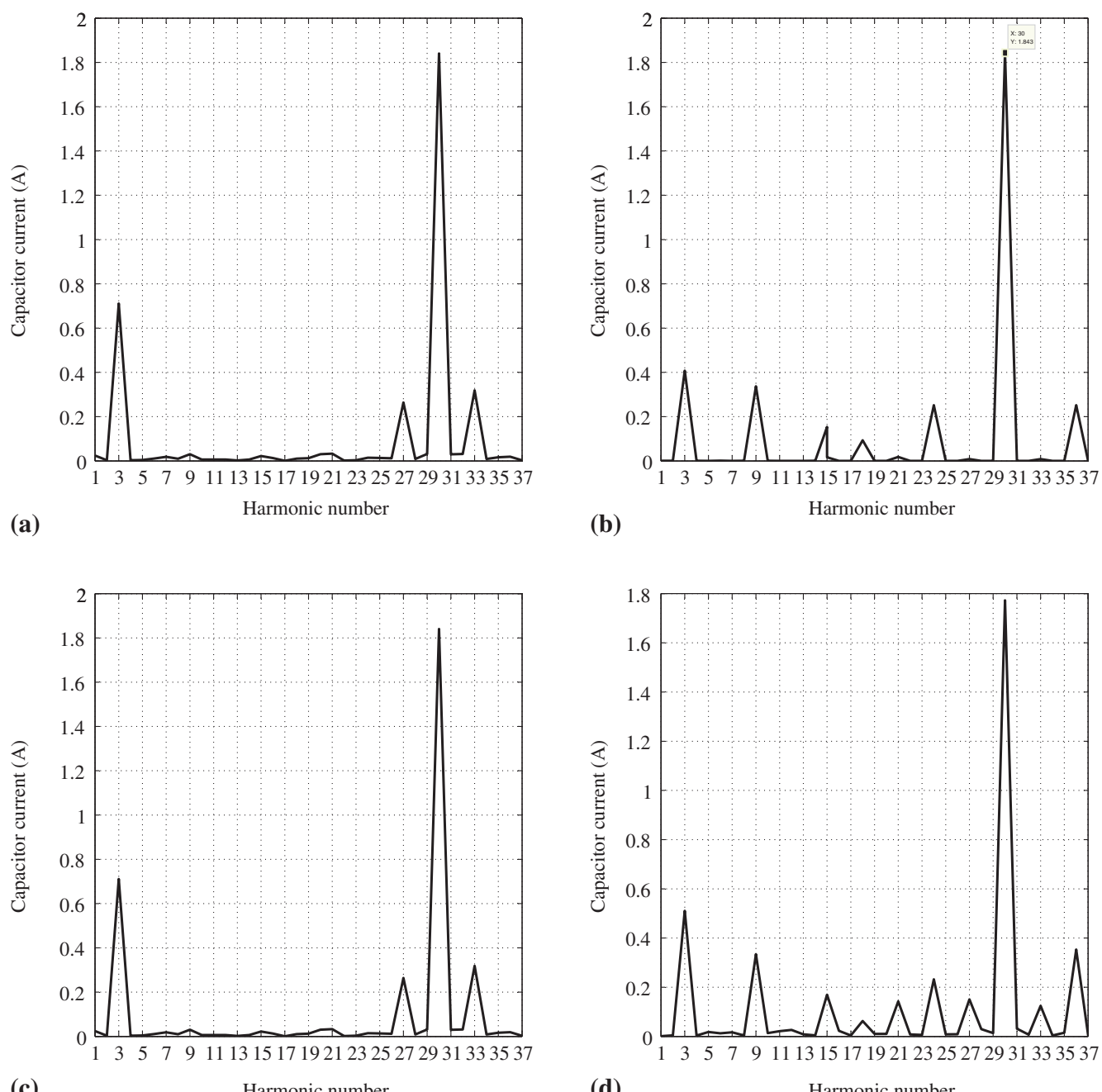

(c)

Harmonic number

(d)

Harmonic number

Figure 14. Analytical evaluated harmonic spectra of capacitor current for $M=0.6$ and $\cos (\phi)=$ 0.844(lag) for (a) SPWM scheme; (b) CSVPWM scheme. Experimentally obtained harmonic spectrum of capacitor current waveform at $i=0.6$ and $\cos (\phi)=0.844$ (lag); (c) SPWM scheme; (d) CSVPWM scheme.

figures 11-16. As can be seen from the spectra in figures 11-16, the analytical and experimental spectra closely match with each other, validating the harmonic analysis presented in this paper.

At each operating condition, the third harmonic current is lower with CSVPWM [parts (b) and (d) in figure 11-16] than with SPWM [parts (a) and (c) in figures 11-16]. As shown by the spectra corresponding to SPWM, the third harmonic is the only significant low frequency component in the DC capacitor current spectrum for this PWM scheme. However, with CSVPWM scheme, there is also a significant presence of ninth-harmonic content in the capacitor current, particularly at high power factors and low modulation indices [see figures 12 and 14]. For both the PWM schemes, the amplitude of the third harmonic component increases with increase in modulation 


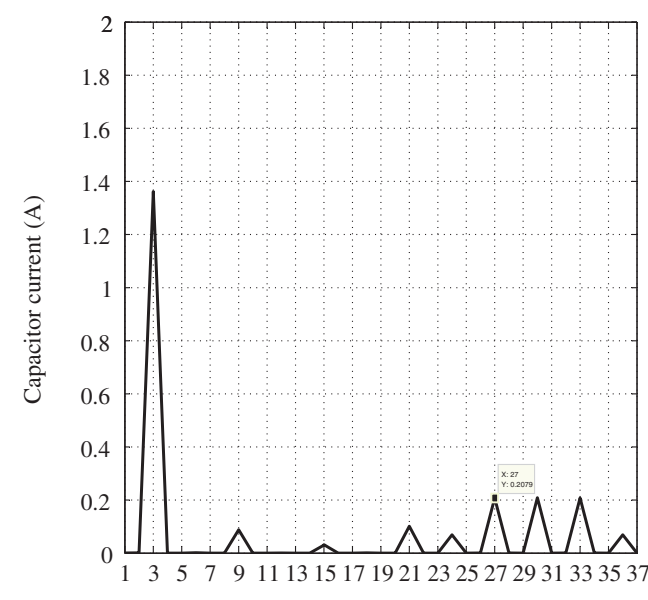

(a)

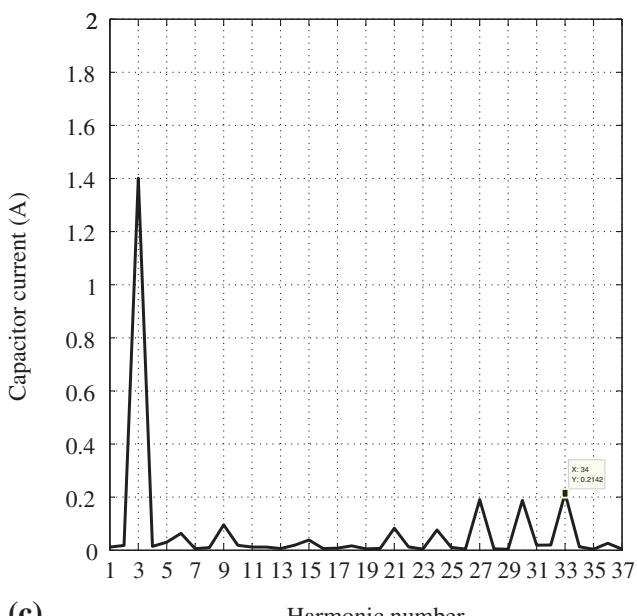

(c)
Harmonic number

Harmonic number
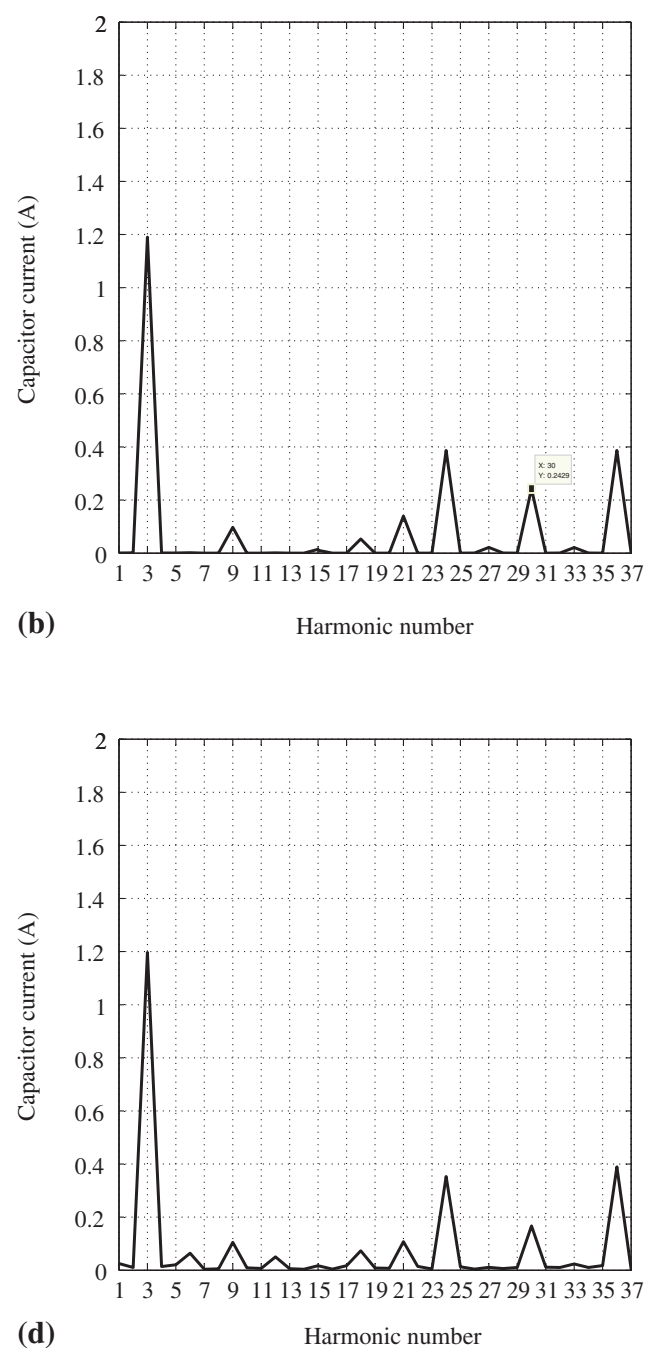

Figure 15. Analytical evaluated harmonic spectra of capacitor current for $M=0.9$ and $\cos (\phi)=$ 0.137(lag) for (a) SPWM scheme; (b) CSVPWM scheme. Experimentally obtained harmonic spectrum of capacitor current waveform at $M=0.9$ and $\cos (\phi)=0.137$ (lag); (c) SPWM scheme; (d) CSVPWM scheme.

index. Also, the third harmonic current decreases with increase in power factor for both the schemes.

\section{Evaluation of power loss in the DC-link capacitor}

The power loss in a DC-link capacitor is on account of the ripple current flowing through it and the ESR of the capacitor. The ESR of the capacitor is dependent on frequency (Kieferndorf et al 2004). The capacitor used is ALCON PG6DI, 450V, 4700uF electrolytic capacitor (ALCON electronics Pvt Ltd 2011). The ESR values of the capacitor at different frequencies, as supplied 


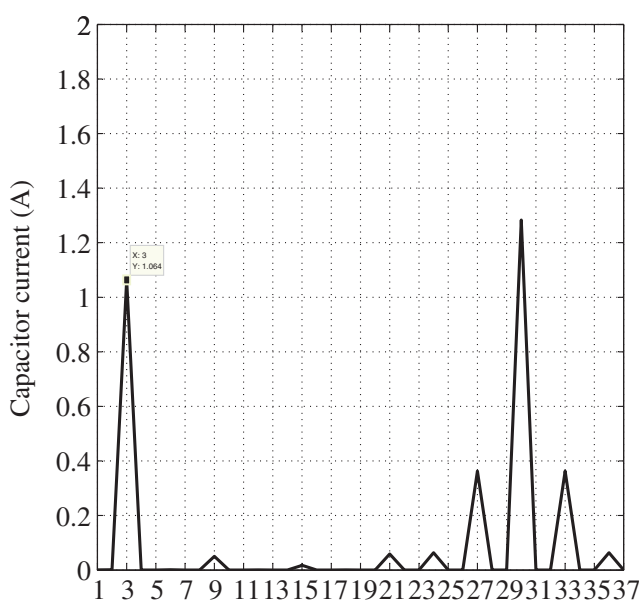

(a)

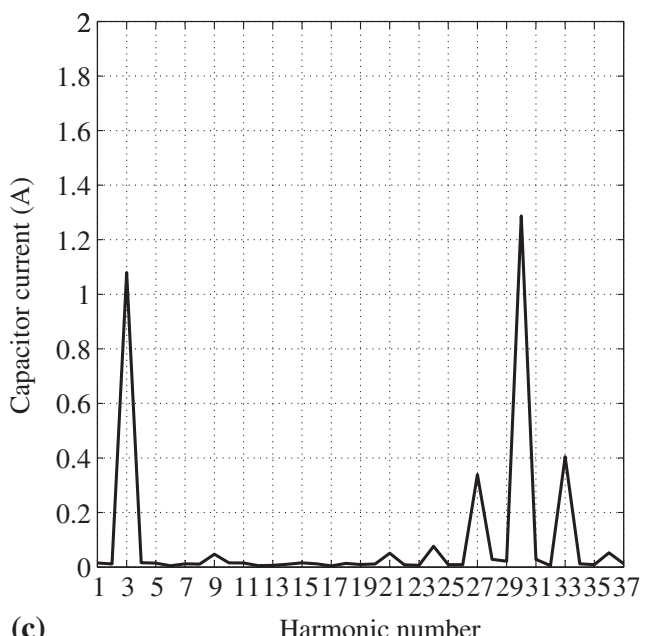

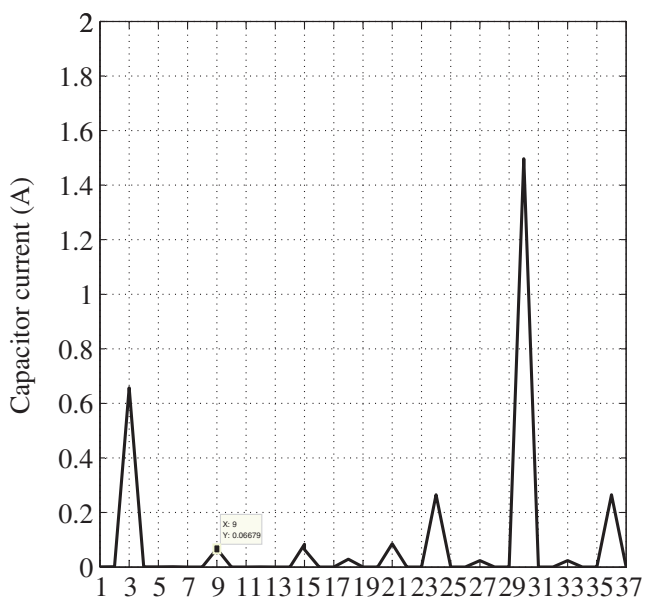

(b)

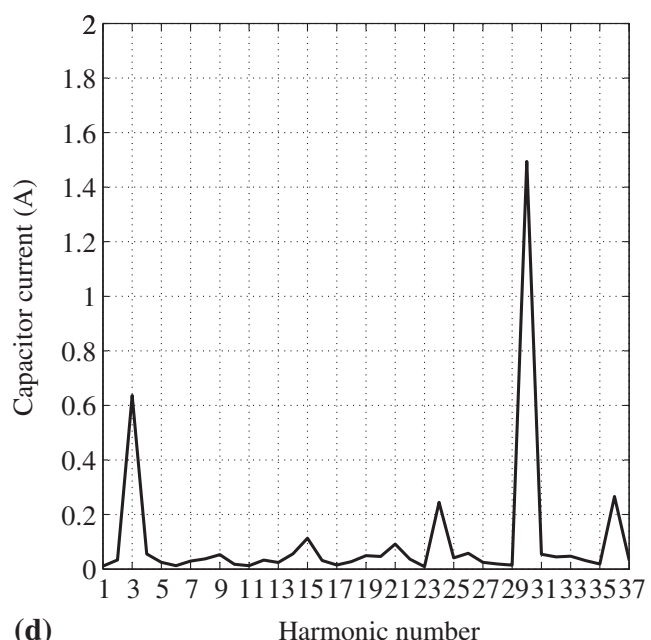

Figure 16. Analytical evaluated harmonic spectra of capacitor current for $M=0.9$ and $\cos (\phi)=$ 0.844(lag) for (a) SPWM scheme; (b) CSVPWM scheme. Experimentally obtained harmonic spectrum of capacitor current waveform at $\mathrm{M}=0.9$ and $\cos (\phi)=0.844(\mathrm{lag})$; (c) SPWM scheme; (d) CSVPWM scheme.

by the manufacturer, are shown in table 6 . A curve fit on these data points is done using MATLAB. The resulting equation for the capacitor ESR at a base temperature of $25^{\circ} \mathrm{C}$ is given in (20), where ' $n$ ' is the harmonic order, and $\operatorname{ESR}(n)$ is the $\operatorname{ESR}$ value at this harmonic frequency. This is shown plotted in figure 17. As shown by the figure, the ESR decreases at first with 'n', and then remains almost a constant at high values of ' $n$ '.

$$
\operatorname{ESR}(n)=\frac{0.0250}{\left(1+\left(0.2025 n^{2}\right)\right)}+0.0280
$$


Table 6. ESR value at various frequencies (Aluminum Electrolytic Capacitors 2011).

\begin{tabular}{lc}
\hline Frequency $(\mathrm{Hz})$ & ESR $(\mathrm{ohm})$ \\
\hline 100 & 0.041 \\
150 & 0.036 \\
300 & 0.032 \\
500 & 0.030 \\
5000 & 0.028 \\
\hline
\end{tabular}

The harmonic components of the capacitor current and the values of ESR at different frequencies are used to calculate the power loss in capacitor as shown in (21). Here $I_{C 1}(n)$ is the RMS value of $n^{\text {th }}$ harmonic of the capacitor current.

$$
P=\sum_{n=1}^{\infty} I_{C 1}^{2}(n) \operatorname{ESR}(n) .
$$

The capacitor power loss is evaluated for both SPWM and CSVPWM schemes at modulation indices of $0.5,0.6$ and 0.9 , and at lagging power factors of 0.137 and 0.844 at each modulation

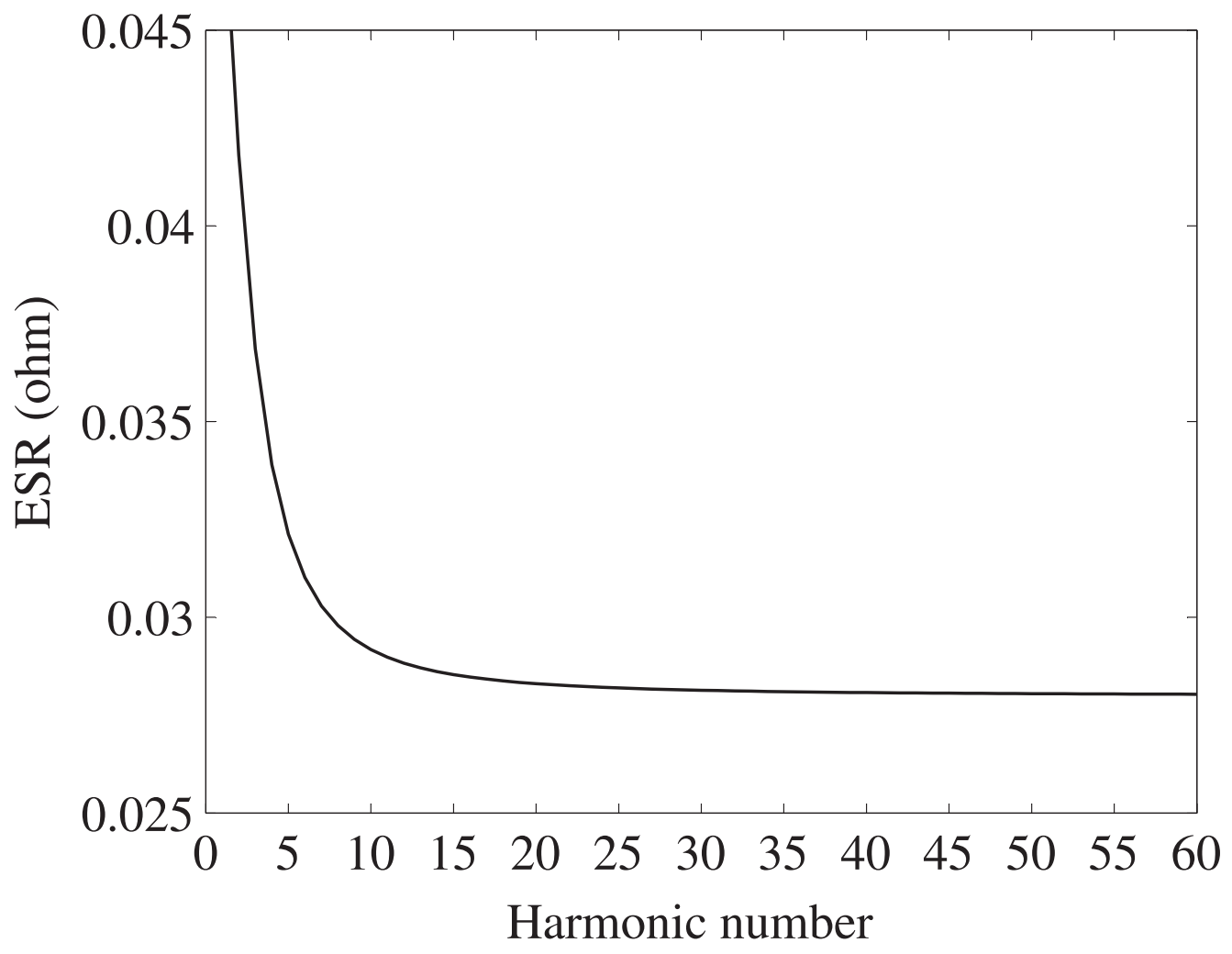

Figure 17. Plot of ESR versus harmonic number. 
Table 7. Power loss estimated at various operating conditions when load current is $4 \mathrm{~A}$.

\begin{tabular}{lcccc}
\hline Modulation index & Load current (A) & Power factor & SPWM & CSVPWM \\
\hline 0.9 & 4 & 0.844 & 0.0625 & 0.0607 \\
0.9 & 4 & 0.137 & 0.0553 & 0.0523 \\
0.6 & 4 & 0.844 & 0.0725 & 0.0684 \\
0.6 & 4 & 0.137 & 0.0347 & 0.0295 \\
0.5 & 4 & 0.844 & 0.0676 & 0.0644 \\
0.5 & 4 & 0.137 & 0.0272 & 0.0240 \\
\hline
\end{tabular}

index. The power losses are evaluated at a load current of 4 A. These are tabulated in table 7 . As seen, the power loss due to the two PWM schemes is quite comparable. However, there is a marginal reduction in the capacitor loss with CSVPWM; this can be attributed to the reduction in third-harmonic current with CSVPWM and also to the fact that ESR at third harmonic frequency is significantly higher than those at the ninth harmonic and switching frequencies. A similar table showing the capacitor power loss at the same operating conditions but at a different load current of $16 \mathrm{~A}$ is shown in table 8 . It can be seen that the capacitor power loss is roughly proportional to square of the current.

\section{Evaluation of voltage ripple in the DC-link capacitor}

The voltage ripple in a DC-link capacitor depends on the RMS current flowing through the capacitor, the ESR of the capacitor and the impedance of the DC-link capacitor. The capacitor voltage ripple is derived as shown in (22). It can be seen from (22), that the voltage ripple consists of two components. One is due to the ESR of the capacitor and another is due to its reactance, both of which are dependent on frequency. The voltage ripple at different frequencies is summed up to calculate the net RMS voltage ripple. In (22), $V_{C 1}(R M S)$ is the RMS voltage ripple across the capacitor, ' $\mathrm{C}$ ' is the capacitance of the DC-link capacitor.

$$
V_{C 1}(R M S)=\sqrt{\sum_{n=1}^{\infty}\left(I_{C 1}(n) \operatorname{ESR}(n)\right)^{2}+\left(\frac{I_{C 1}(n)}{100 \pi n C}\right)^{2}} .
$$

The RMS capacitor voltage ripple at two different current ratings of $4 \mathrm{~A}$ and $16 \mathrm{~A}$ is evaluated for both SPWM and CSVPWM schemes at the same operating conditions as above. These are tabulated in table 9 and table 10, respectively. It can be seen from tables 9 and 10 that the voltage

Table 8. Power loss estimated at various operating conditions when load current is 16A.

\begin{tabular}{lcccc}
\hline \multirow{2}{*}{ Modulation index } & Load current(A) & Power factor & SPWM & CSVPWM \\
\hline 0.9 & 16 & 0.844 & 0.998 & 0.970 \\
0.9 & 16 & 0.137 & 0.885 & 0.837 \\
0.6 & 16 & 0.844 & 1.13 & 1.09 \\
0.6 & 16 & 0.137 & 0.555 & 0.472 \\
0.5 & 16 & 0.844 & 1.082 & 0.1 .031 \\
0.5 & 16 & 0.137 & 0.435 & 0.382 \\
\hline
\end{tabular}


Table 9. RMS voltage ripple estimated at various operating conditions when the load current amplitude is $4 \mathrm{~A}$.

\begin{tabular}{lcccc}
\hline & & & \multicolumn{2}{c}{ Voltage ripple (V) } \\
\cline { 4 - 5 } Modulation index & Load current(A) & Power factor & SPW & CSVPWM \\
\hline 0.9 & 4 & 0.844 & 0.1773 & 0.1157 \\
0.9 & 4 & 0.137 & 0.2225 & 0.1947 \\
0.6 & 4 & 0.844 & 0.1255 & 0.0854 \\
0.6 & 4 & 0.137 & 0.1489 & 0.0925 \\
0.5 & 4 & 0.844 & 0.1078 & 0.0765 \\
0.5 & 4 & 0.137 & 0.1215 & 0.0751 \\
\hline
\end{tabular}

Table 10. RMS voltage ripple estimated at various operating conditions when the load current amplitude is $16 \mathrm{~A}$.

\begin{tabular}{lcccc}
\hline & & & \multicolumn{2}{c}{ Voltage ripple (V) } \\
\cline { 4 - 5 } Modulation index & Load current(A) & Power factor & SPWM & CSVPWM \\
\hline 0.9 & 16 & 0.844 & 0.7090 & 0.4629 \\
0.9 & 16 & 0.137 & 0.8899 & 0.7787 \\
0.6 & 16 & 0.844 & 0.5020 & 0.3416 \\
0.6 & 16 & 0.137 & 0.5956 & 0.3705 \\
0.5 & 16 & 0.844 & 0.4311 & 0.3060 \\
0.5 & 16 & 0.137 & 0.4979 & 0.3005 \\
\hline
\end{tabular}

ripple due to CSVPWM scheme is lesser than that due to SPWM scheme. This can be attributed to the reduction in third harmonic content in capacitor current due to CSVPWM scheme.

\section{Conclusion}

Harmonic analysis of the DC capacitor current in a neutral-point clamped (NPC) inverter based on the double Fourier series and geometric wall method is presented in this paper. The harmonic spectra pertaining to sine-triangle PWM (SPWM) and conventional space vector PWM (CSVPWM) schemes are evaluated and compared at different operating conditions. The analytically obtained harmonic spectra are validated through measured harmonic spectra at various operating conditions.

The third harmonic component is found to be the only significant low-frequency component in the capacitor current in case of SPWM. However, with CSVPWM, significant ninth harmonic current is also observed, particularly at high power factors and low modulation indices. On the other hand, the third harmonic current with CSVPWM is always lower than that with SPWM at any operating point. For both PWM schemes, the third harmonic current increases with increase in modulation index, but decreases with increase in power factor. With a knowledge of the DCcapacitor current harmonic spectrum, the power loss and voltage ripple in the DC capacitor is estimated at different operating conditions for both SPWM and CSVPWM schemes. 


\section{References}

ALCON electronics Pvt Ltd 2011 Aluminum electrolytic capacitors - catalogue no. PG-6DI-00-00, URL: www.icd-sales.com

Aluminum Electrolytic Capacitors - catalogue no. PG-6DI-00-00 ALCON electronics Pvt Ltd, Jan-2011. URL: www.icd-sales.com

Bierhoff M H and Fuchs F W 2008 DC-link harmonics of three-phase voltage-source converters influenced by the pulsewidth-modulation strategy: An analysis. IEEE Trans. Ind. Electron. 55(5): 2085-2092

Choi U M, Lee J S and Lee K B 2014 New modulation strategy to balance the neutral-point voltage for three-level neutral-clamped inverter systems. IEEE Trans. Energy Conv. 29(1): 91-100

Das S 2013 Study on pulsewidth modulation techniques for a neutral-point-clamped voltage source inverter. $\mathrm{PhD}$ Thesis, Indian Institute of Science, Bangalore, May 2013

Gasperi M L 1997 A method for predicting the expected life of bus capacitors. Proc. Conf. Industry Appl. 2: $1042-1047$

Gopalakrishnan K S, Soumitra Das and Narayanan G 2011 Analytical expression for RMS DC link capacitor current in a three-level inverter. Proc. Conf. Centenary. IISc Bangalore, India

Gopalakrishnan K S and Narayanan G 2013 Harmonic analysis of DC-link capacitor current in sinusoidally modulated neutral-point-clamped inverter. National Power Electronics Conference

Holmes D G and Lipo T A 2003 Pulse width modulation for power converters. Piscataway, NJ: IEEE Press

Kieferndorf F D, Forster M and Lipo T A 2004 Reduction of DC-bus capacitor ripple current with PAM/PWM converter. IEEE Trans. Ind. Appl. 40(2): 607-614

Kolar J W and Round S D 2006 Analytical calculation of the RMS current stress on the DC-link capacitor of voltage-PWM converter systems. IEE Proc. Electric Power., Appl. 153(4): 535-543

Kouro Samir, Malinowski M, Gopakumar K, Pou J, Franquelo L G, Wu B, Rodriguez J, Pérez M A and Leon J I 2010 Recent advances and industrial applications of multilevel converters. IEEE Trans. Ind. Electron. 57(8): 2553-2580

Lee Y H, Kim D H and Hyun D S 2000 Carrier based SVPWM method for multi-level system with reduced HDF [harmonic distortion factor]. Industry Applications Conference 3: 1996-2003

Lee J S and Lee K B 2014 New modulation techniques for a leakage current reduction and a neutral-point voltage balance in transformerless photovoltaic systems using a three-level inverter. IEEE Trans. Power Electron. 29(4): 1720-1732

Lekha S 2013 Comparison of two-level and three-level neutral-point clamped inverters in automotive application MASc Thesis, University of Concordia, Quebec Canada

McGrath B P and Holmes D G 2002 An analytical technique for the determination of spectral components of multilevel carrier-based PWM methods. IEEE Trans. Ind. Electron. 49(4): 847-857

Moynihan J F, Egan M G and Murphy J M D 1998 Theoretical spectra of space-vector-modulated waveforms. IEE Trans. Elec. Power Appl. 145(1): 17-24

Orfanoudakis G I, Sharkh S M, Yuratich M A and Abusara M A 2010 Loss comparison of two and threelevel inverter topologies. In: Proc. IET Int. Conf. Power Electron., Machines and Drives 1-6

Orfanoudakis G I, Yuratich M A and Sharkh S M 2013a Analysis of dc-link capacitor current in three-level neutral point clamped and cascaded H-bridge inverters. IET Trans. Power. Electron. 6(7): 1376-1389

Orfanoudakis G I, Yuratich M A and Sharkh S M 2013b Nearest-vector modulation strategies with minimum amplitude of low-frequency neutral-point voltage oscillations for the neutral-point-clamped converter. IEEE Trans. Power Electron. 28(10): 4485-4499

Rodriguez J, Bernet S, Steimer P K and Lizama I E 2010 A survey on neutral-point-clamped inverters. IEEE Trans. Ind. Electron. 57(7): 2219-2230

Teichmann R and Bernet S 2005 A comparison of three-level converters versus two-level converters for low-voltage drives, traction, and utility applications. IEEE Trans. Ind. Appl. 41: 855-865

Wang Fei 2002 Sine-triangle versus space-vector modulation for three-level PWM voltage-source inverters. IEEE Trans. Ind. Appl. 38(2): 500-506 